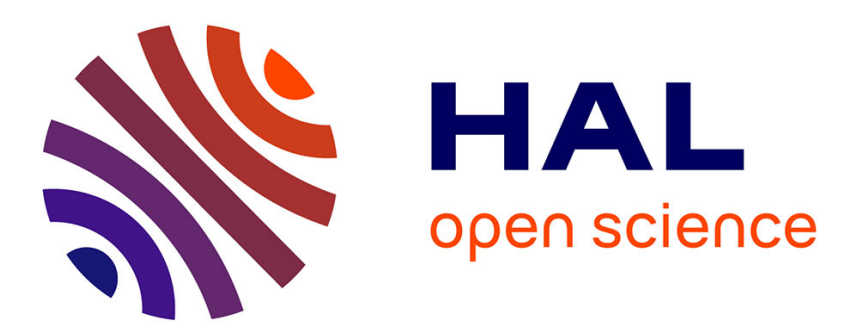

\title{
Using UKCP09 probabilistic climate information for UK water resource planning
}

B.V. Christierson, Jean-Philippe Vidal, S.D. Wade

\section{To cite this version:}

B.V. Christierson, Jean-Philippe Vidal, S.D. Wade. Using UKCP09 probabilistic climate information for UK water resource planning. Journal of Hydrology, 2012, 424-425, p. 48 - p. 67. 10.1016/j.jhydrol.2011.12.020 . hal-00675607

\section{HAL Id: hal-00675607 https://hal.science/hal-00675607}

Submitted on 1 Mar 2012

HAL is a multi-disciplinary open access archive for the deposit and dissemination of scientific research documents, whether they are published or not. The documents may come from teaching and research institutions in France or abroad, or from public or private research centers.
L'archive ouverte pluridisciplinaire HAL, est destinée au dépôt et à la diffusion de documents scientifiques de niveau recherche, publiés ou non, émanant des établissements d'enseignement et de recherche français ou étrangers, des laboratoires publics ou privés. 
Author version of the manuscript accepted for publication in the Journal of Hydrology.

Christierson, B. v., Vidal, J.-P., Wade, S. D. (2012) Using UKCP09 probabilistic climate information for UK water resource planning. Journal of Hydrology. doi: $10.1016 /$ j.jhydrol.2011.12.020

The original publication is available at:

http://dx.doi.org/10.1016/j.jhydrol.2011.12.020 


\title{
Using UKCP09 probabilistic climate information for UK water resource planning
}

\author{
Birgitte von Christierson ${ }^{\mathrm{a}}$, Jean-Philippe Vidal ${ }^{\mathrm{b}, *}$, Steven D. Wade ${ }^{\mathrm{a}}$ \\ ${ }^{a}$ HR Wallingford, Howbery Park, OX10 8BA Wallingford, UK \\ ${ }^{b}$ Irstea, UR HHLY, 3 bis quai Chauveau - CP 220, F-69336 Lyon, France
}

\begin{abstract}
Water companies in the United Kingdom have considered climate change in their water resources plans for more than a decade through studies funded by UK Water Industry Research (UKWIR). This paper presents an initial assessment of the impact of the UK Climate Projections 2009 (UKCP09) on river flows at a national scale for the 2020s under the A1B scenario and the implications for water resource planning. A daily hydrological modelling framework based on two conceptual model structures and the Generalized Likelihood Uncertainty Estimation (GLUE) methodology has been applied to 70 catchments across the UK. A Latin Hypercube Sampling approach was adopted to handle the probabilistic nature of UKCP09. Results show a decrease in mean annual flow over most of the UK, with negative median values of all monthly changes except in winter over the western and northern mountainous areas. Furthermore the results indicate a high likelihood of a significant decline in summer flows. An analysis of variance shows that the main uncertainty in river flow changes comes from the spread in climate projections. Finally results are found to be consistent with a previous UKWIR assessment based on individual projections from 6 Global Climate Models (GCMs) under the A2 scenario. The reduction in summer low-flows, critical for water resources, appears however more limited with UKCP09. Although most expected changes are within natural variability, the drier conditions overall and the greater spread of results with respect to previous assessments indicates a need for testing the robustness of water resource plans.
\end{abstract}

Keywords: climate change, probabilistic, river flow, UK, uncertainty, UKCP09

\section{Introduction}

The potential impacts of climate change have been considered in UK water resources planning for a decade (Subak, 2000; Arnell and Delaney, 2006; Charl-

\footnotetext{
* Corresponding author

Email address: jean-philippe.vidal@irstea.fr (Jean-Philippe Vidal)
} 
ton and Arnell, 2011; Hall et al., 2011). This could be achieved notably thanks to a series of national-scale studies funded by UK Water Industry Research (UKWIR) and the Environment Agency (EA) that provided projected changes in monthly river flows and annual average recharge for UK catchments along with practical methods for including such changes in water resource plans (see, e.g., Vidal and Wade, 2007a; von Christierson et al., 2009). Table 1 provides an overview of the main climate change studies with reference to the five-year water company Asset Management Plans (AMPs). As new climate change projections become available studies to produce new hydrological scenarios and accompanying guidance are initiated and subsequently incorporated in policy documents for water resources planning (Environment Agency, 2009a).

Table 1: Review of the integration of climate change impacts on UK water resources planning, including timelines covering UK Asset Management Plans (AMPs). Factors here refer to changes between a future time slice and a present-day period.

\begin{tabular}{|c|c|c|c|}
\hline AMP Period & $\begin{array}{l}\text { Climate } \\
\text { change } \\
\text { scenarios }\end{array}$ & $\begin{array}{l}\text { Water Industry } \\
\text { Research tech- } \\
\text { nical documents } \\
\text { and guidelines }\end{array}$ & Policy documents \\
\hline 1 (1990-1995) & $\begin{array}{l}\text { CCIRG } \\
(1991,1996)\end{array}$ & - & - \\
\hline $2(1995-2000)$ & $\begin{array}{l}\text { UKCIP98 } \\
\text { (Hulme and } \\
\text { Jenkins, } \\
\text { 1998) }\end{array}$ & $\begin{array}{l}\text { UKWIR97 (Ar- } \\
\text { nell et al., 1997), } \\
\text { flow factors re- } \\
\text { calculated based } \\
\text { on UKCIP98 }\end{array}$ & - \\
\hline $3(2000-2005)$ & $\begin{array}{l}\text { UKCIP02 } \\
\text { (Hulme } \\
\text { et al., 2002) }\end{array}$ & $\begin{array}{l}\text { UKWIR02 (Ar- } \\
\text { nell, 2002) }\end{array}$ & $\begin{array}{l}\text { Water resources planning } \\
\text { guidelines (Environment } \\
\text { Agency, 2003) }\end{array}$ \\
\hline $4(2005-2010)$ & $\begin{array}{l}\text { UKWIR06 } \\
\text { (Vidal } \\
\text { and Wade, } \\
\text { 2008a) }\end{array}$ & $\begin{array}{l}\text { UKWIR06 } \\
\text { (Prudhomme } \\
\text { et al., 2005; } \\
\text { Wade et al., } \\
2005, \text { 2006; } \\
\text { Beven et al., } \\
2006 ; \text { Vidal and } \\
\text { Wade, 2007a,b) }\end{array}$ & $\begin{array}{l}\text { Water resources plan- } \\
\text { ning guideline (Environ- } \\
\text { ment Agency, 2007) + } \\
\text { supplementary guidance } \\
\text { on climate change (Ar- } \\
\text { nell and Reynard, 2007), } \\
\text { Water resources planning } \\
\text { guideline (Environment } \\
\text { Agency, 2008) }\end{array}$ \\
\hline $5(2010-2015)$ & $\begin{array}{l}\text { UKCP09 } \\
\text { (Murphy } \\
\text { et al., 2009) }\end{array}$ & $\begin{array}{l}\text { UKWIR09 (von } \\
\text { Christierson } \\
\text { et al., 2009) }\end{array}$ & In progress \\
\hline
\end{tabular}

Each of the impact studies in Table 1 had to deal with a different set of national climate scenarios, but also with the associated uncertainty, which differed from one set to the other (see the review of Hulme and Dessai, 2008). For 
example, CCIRG (1991) provided climate change information based on several General Circulation Models (GCMs) whereas the following three reports from the Climate Change Impact Review Group (CCIRG, 1996) and the UK Climate Impact Programme (UKCIP98a and UKCIP02; Hulme and Jenkins, 1998; Hulme et al., 2002) essentially based their analysis on projections from one climate model. Different emissions scenarios have also been considered from the UKCIP98 report onwards. In spite of these diverse treatments of uncertainty the results were however consistently presented as individual projections, e.g., the "medium-high" scenario from the UKCIP02 report. The latest UK climate scenarios (UKCP09, Murphy et al., 2009) provide for the first time probabilistic projections, aiming at sampling different types of uncertainties through the use of large "perturbed physics" ensemble of the Met Office HadCM3 climate model. The probabilities encapsulate uncertainties from different sources: natural variability, climate models with different parameters and process descriptions, outputs of models from the Met Office and other institutions, etc. The probabilistic nature of UKCP09 represents an opportunity to move from a scenario-based impact and adaptation framework (see all previous studies in Table 1) to a risk-based decision-making framework (see Hall et al., 2011, for a first attempt). This however first requires to propagate the probabilistic climate information through the hydrological modelling step, which is particularly challenging (New et al., 2007; Stainforth et al., 2007).

This paper presents a practical method for using probabilistic information in future climate change impact assessments developed through a recent project undertaken on behalf of UKWIR (von Christierson et al., 2009). It also aims at assessing how taking account of the new UKCP09 probabilistic projections will affect the climate change impact assessments undertaken by the water companies for draft Water Resources Management Plans (WRPs) for the last Periodic Review (PR09). These assessments, submitted in autumn 2009 (Charlton and Arnell, 2011), were indeed based on the previous national-scale impact study achieved in 2008 (Vidal and Wade, 2007a). The main challenge of the study was to develop a practical and sufficiently credible approach to undertaking the assessment in a relatively short space of time whilst making use of a complex dataset. It introduces a simplified multi-scenarios approach developed to specify plausible ranges of impacts on river flows for assessing the sensitivity of the latest water resources plans. The method does not make full use of the new probabilistic data sets but nevertheless gives a useful indication of the differences between the UKCP09 and the previous projections in terms of river flow and provides a first attempt at developing a practical method for using probabilistic information in future climate change impact assessments for water resource planning.

The purpose of this paper is therefore threefold: (1) developing a practical method for using probabilistic climate projections in a national-scale hydrological impact assessment, (2) comparing results with the previous nationalscale assessment currently used for Water Resources Management Plans, and (3) quantifying the uncertainties in changes in river flows and identifying their sources. The first two objectives are driven by the industry context and propose 
a both innovative and practical framework to deal with recent developments in climate projections. The last objective is to propose for the first time a nationalscale assessment of uncertainties in future river flows that include both climate and hydrological modelling uncertainties.

The paper is structured as follows. Section 2 introduces the 70 modelled catchments, observed river flow and climate data. This paper makes use of different sets of climate projections for the 2020s. First, the national-scale projections derived for the previous water resources assessment, called UKWIR06 projections (Vidal and Wade, 2007a), and second, two datasets provided by the Met Office as part of the UK Climate Projections: the actual UKCP09 probabilistic changes (Murphy et al., 2009, chap. 4), and an ensemble of regional projections obtained with 11 variants of the Met Office HadRM3 Regional Climate Model (Murphy et al., 2009, chap. 5).

Section 3 describes the overall modelling framework. It details the method used for sampling probabilistic projections and the approach adopted to assess the structure and parameter uncertainties in the hydrological modelling. In order to identify the modifications induced solely by the use of new climate projections on future river flows, this paper has aimed to replicate as closely as possible the hydrological modelling approach developed by Vidal and Wade (2007a) from the previous national-scale assessment.

Section 4 presents national-scale results derived from the sampled UKCP09 probabilistic projections, first in terms of monthly precipitation and evapotranspiration, and then in terms of future river flows. Albeit some assessments have been done on changes in low-flows (von Christierson et al., 2009, see), this paper will focus on changes in annual and monthly flows. Climate and hydrological changes derived from UKCP09 probabilistic projections are then compared with changes derived from UKWIR06 projections at the national scale. A more detailed comparison of changes in river flows derived from the three climate datasets is moreover performed for two specific contrasted catchments, the Thames@Kingston and the Ribble@Arnford.

The decomposition of uncertainty between future climate and hydrological modelling is investigated in Section 5. Section 6 discusses the limitations and assumptions of this study and provides some elements for further work. UKCP09 implications for UK water resource planning are finally examined in Section 7.

\section{Data}

\subsection{Catchments and flow data}

Catchment selection was based on: (1) consistency with previous studies (Arnell et al., 1997; Arnell, 2002; Vidal and Wade, 2007a) to allow for comparison between results; (2) low levels of artificial influences (abstractions and discharges) or availability of naturalised flow series; (3) reasonable geographical spread of catchments throughout the UK; and (4) availability of rainfall, temperature and river flow data over the 1961-1990 baseline period. Figure 1 shows the location of the 70 selected catchments. Most of these are part of a network of 
benchmark catchments (Bradford and Marsh, 2003) recently used for assessing trends in runoff, low flows and floods (Hannaford and Marsh, 2006, 2008). Daily flow data have been retrieved from the National River Flow Archive $\left(\mathrm{NRFA}^{1}\right)$. Existing naturalised time series for Lee@FeildesWeir and Thames@Kingston have been preferred to raw gauged time series. At least twenty years of data are available for more than 50 catchments, and only one catchment holds less than 10 years of data.

Two catchment case studies are used in this study for presenting detailed results. The Ribble@Arnford is a small mountainous catchment located in NorthWest of England. It covers a moorland area with an altitude ranging between 110 and $700 \mathrm{~m}$, and is exposed to high precipitation totals falling preferentially from late summer to late winter (Vidal and Wade, 2008b). It has a wholly natural flow regime with a low baseflow index. The Thames@Kingston is a large catchment located in the south-east of England, one of the driest region in the UK, and it has a flow regime sustained by groundwater. This catchment experiences high levels of abstractions for meeting the demands for drinking water of the London area, so the present balance between water supply and demand is already in deficit (Environment Agency, 2009b). The effects of climate change on water resources on this specific catchment have therefore been extensively studied in previous works (see, e.g., Wilby and Harris, 2006; Manning et al., 2009).

\subsection{Observed climate data}

Daily catchment rainfall was provided by the Met Office (Perry et al., 2009) for the 1961-1990 period currently used as the baseline period in climate change impact assessments. Daily potential evapotranspiration (PET) time series were built using a formula based on mean temperature (Oudin et al., 2005a) especially established for conceptual hydrological models as the ones used here. This formula proved very efficient in terms of streamflow simulation efficiency when compared with 27 different PET formulas using data from more than 300 catchments under various climates (Oudin et al., 2005b). The dependence on temperature only makes it well suited in a climate change context where only few variables are usually available, as it is the case with UKCP09 probabilistic projections. The temperature-based formula has been applied to monthly temperature from the gridded data set derived by Perry and Hollis (2005). Results have been allocated to the middle Julian day of each calendar month and interpolated to the daily time scale with a cubic spline algorithm (de Boor, 1978) to obtain daily time series. This temporal disaggregation approach is much more reliable than the traditionally used sine curve method based on mean PET (Wilby and Harris, 2006) as it takes account of within-year temporal shifts which are projected to occur in a changed climate. The implications of this choice of PET calculation is further discussed in Section 6 .

${ }^{1}$ www.ceh.ac.uk/data/nrfa/ 


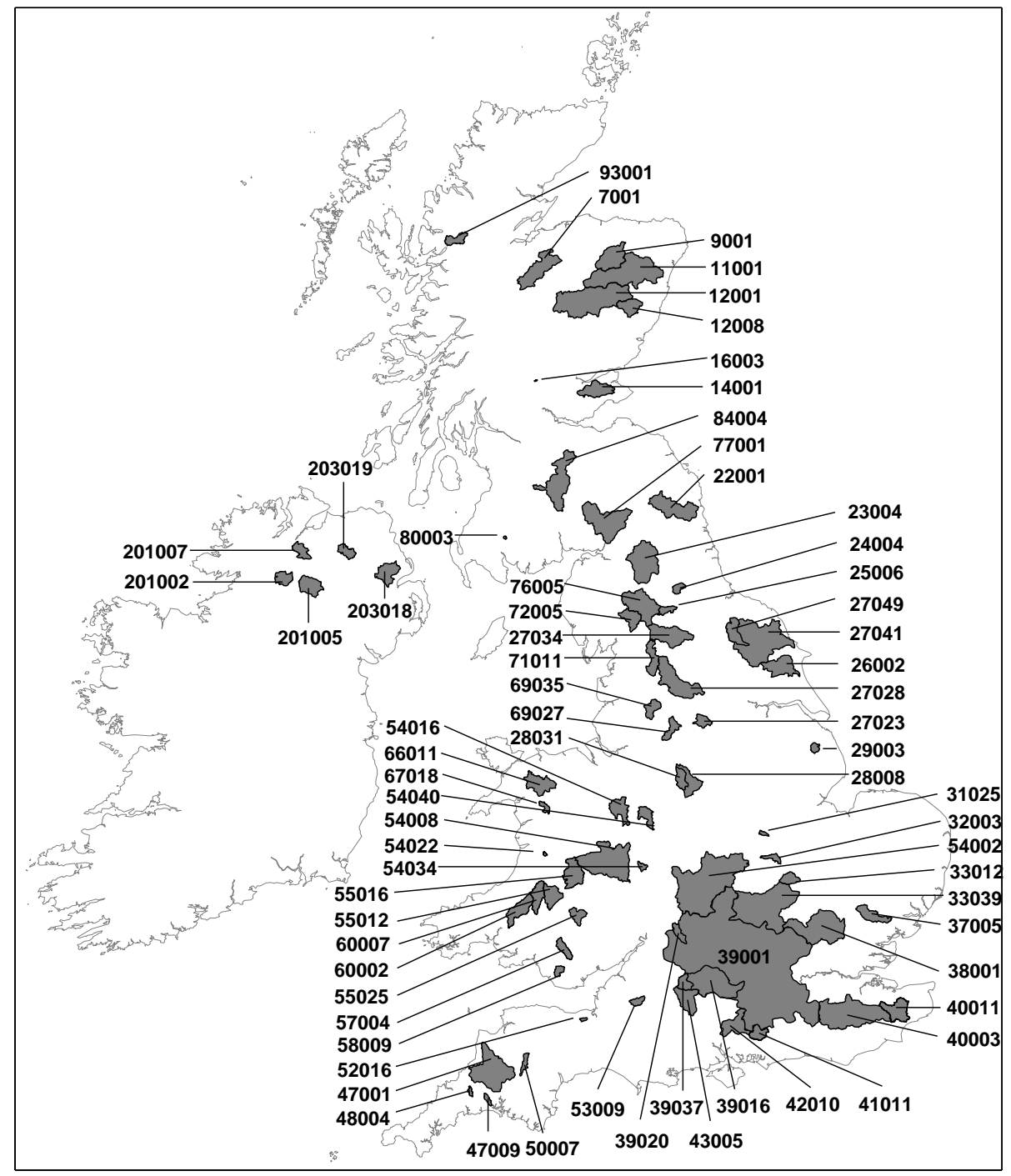

Figure 1: Location of catchment case studies. Numbers refers to NRFA IDs. Manifold@Ilam (28031) is a subcatchment of Dove@RocesterWeir (28008); Coln@Bibury (39020) and Kennet@Theale (39016) are subcatchments of Thames@Kingston (39001); Kennet@Marlborough (39037) is a subcatchment of Kennet@Theale (39016). 


\subsection{Climate projections}

Three climate data sets are used here: (1) the UKCP09 probabilistic changes, (2) an ensemble of projections with 11 variants of the Met Office HadRM3 Regional Climate Model (RCM), and (3) the UKWIR06 projections derived for the previous national-scale assessment of water resources.

UKCP09 probabilistic changes. UKCP09 presents an approach that incorporates improvements in the Met Office Hadley Centre's climate models into a statistical framework for presenting probabilistic climate change data (Murphy et al., 2009). The UKCP09 approach seeks to sample the uncertainties in future climates related to two sources of climate model error: parameter and structural error. The effects of parameter uncertainties have been explored by construction of an ensemble of variants of the HadCM3 climate model and development of an emulator trained on model results to reproduce a distribution consistent with any parameter combination. Structural uncertainty has been examined by incorporating the results from $13 \mathrm{GCMs}$ in the probability distribution using a statistical framework devised by Goldstein and Rougier (2004). HadCM3 projections have then been downscaled based on a further ensemble of 11 variants of the regional climate model HadRM3, and a statistical procedure has been applied to build local-scale distribution of changes for various climate variables. Detailed information about the generation of UKCP09 climate projections are given by Murphy et al. (2007) and Murphy et al. (2009, chap. 3).

Available outputs for users are statistical distributions of monthly and seasonal climate change factors (between 1961-1990 and a future time slice) given as samples of 100000 members, for different UK administrative and river-basin regions as well as for individual $25 \mathrm{~km}$ grid squares over the UK (Murphy et al., 2009, p. 18). Such outputs are moreover available for each of the following 3 emissions scenario: B1 (low), A1B (medium, used here) or A1FI (high) (Nakićenović et al., 2000). Finally, change factor distributions are available for several time slices of the 21st century, and the period selected here is the 2020s (2011-2040) because of its relevance for water resource planning. Variables considered here are precipitation and temperature.

As there is no correlation between distribution samples of changes from one grid square to the next (Murphy et al., 2009, chap. 1), it is not possible to average outputs from several adjacent grid squares that may cover a single catchment of interest. Due to the national extent of this study which gathers both small and large catchments, it was decided to use monthly probabilistic factors for the 23 river-basin regions given by Murphy et al. (2009, p. 18). Figure 2 compares regional and grid factors for the Ribble@Arnford, located in the North-West England region which is characterized by a relatively high spatial variability of precipitation. This figure makes use of violin plots (Hintze and Nelson, 1998) which trace full density distributions instead of only quartiles in box plots. It shows that the differences between regional and grid monthly factors are negligible for temperature and remain small for precipitation. The use of regional factors thus seems a reasonable assumption, but it should be kept in mind that there may be local differences for precipitation in particular. 

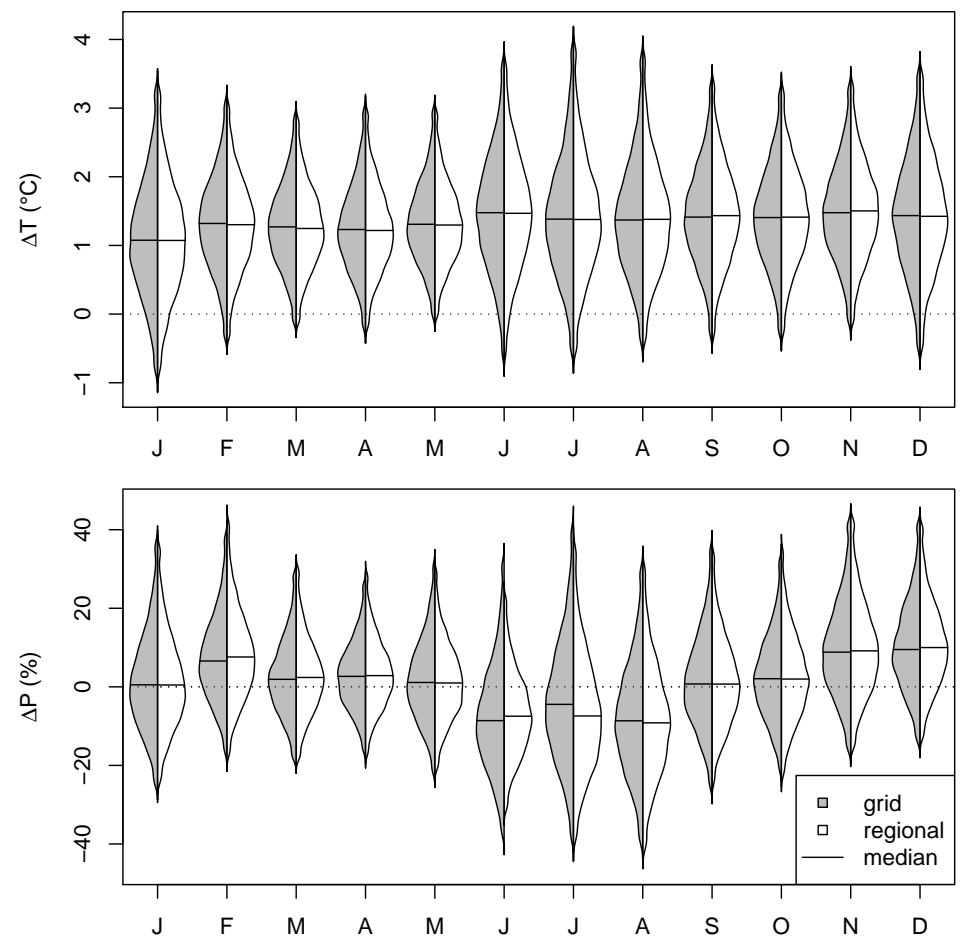

Figure 2: Comparison of temperature and precipitation UKCP09 probability distributions of monthly factors for the Ribble@Arnford catchment under the A1B emissions scenario, show as violin plots. In grey, factors for the closest $25 \mathrm{~km}$ grid cell, in white factors for the North West England river-basin region. 
HadRM3 projections. 11 variants of the HadRM3 RCM have been created by the Met Office in order to dynamically downscale global climate model results as part of UKCP09 (see Murphy et al., 2007, for details on the overall process). The projections comprise an 11 -member ensemble of $25 \mathrm{~km}$-resolution transient climate projections over the UK under the A1B emissions scenario. Their main advantages compared to the UKCP09 probabilistic changes is their availability as continuous spatio-temporal projections. However, the 11-member ensemble does not incorporate the full range of uncertainty available in the UKCP09 projections. In this work, RCM projections have been used only for the two catchment case studies.

UKWIR06 projections. The UKWIR06 projections have been used as the driving projections for the previous national-scale impact assessment (Vidal and Wade, 2007a). These were derived from global climate projections through a downscaling method called BLS - for Bias-corrected Local Scaling - and described in detail by Vidal and Wade (2008a). The method was based on disaggregation and bias-correction schemes initially developed by Wood et al. (2002) for seasonal forecasting and now widely used for climate change impact assessment on water resources (see, e.g., Maurer et al., 2010). The BLS method consists of the following steps: (1) building appropriate time series from land areas covered by GCM sea cells; (2) correcting monthly GCM output inherent biases through quantile-quantile transformation at the GCM spatial scale; and (3) disaggregating bias-corrected outputs to a finer scale by using monthly spatial anomalies of observations. An assessment of the BLS method against other dynamical and statistical downscaling techniques can be found in Vidal and Wade (2008b). An improved version of this method has been recently applied within the IMAGINE2030 project (Sauquet et al., 2009) to build climate forcings for hydrological models and reservoir operation models in order to assess the impact of climate change on hydropower in the French Pyrenees mountain range (Vidal and Hendrickx, 2010). The UKWIR06 projections have also been used to assess the impact of climate change on meteorological droughts over the UK (Vidal and Wade, 2009).

The UKWIR06 projections considered here consist of transient monthly projections for precipitation and temperature at a $5 \mathrm{~km}$ spatial resolution over the UK (Vidal and Wade, 2008b) for the 2020s under the A2 emissions scenario, which corresponds to the medium-high scenario from the previous UK climate assessment (UKCIP02, Hulme et al., 2002). They are available for the 6 GCMs that were used for the Third Assessment Report of the IPCC (2001).

\section{Methods}

Figure 3 illustrates the methodology applied to compute distributions of monthly flow factors from the UKCP09 monthly change factors. The Latin Hypercube Sampling applied to UKCP09 distributions is described in Section 3.1 and Section 3.2 details the methods applied to all three climate data sets to 


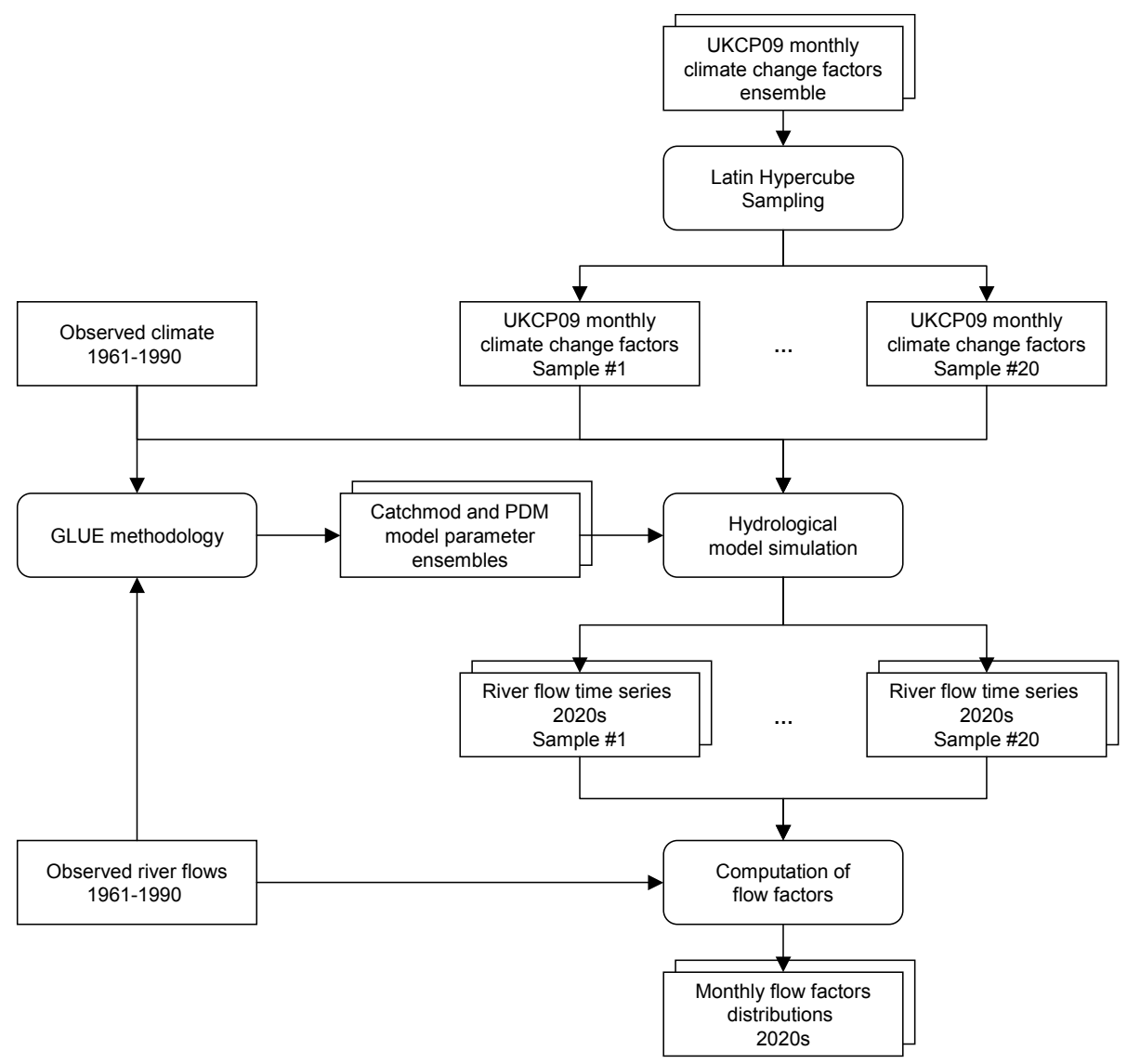

Figure 3: Schematic framework of the hydrometeorological process for deriving river flow factors for the 2020s from UKCP09 climate change distributions (see text for details)

derive daily time series forcings for the 2020s. The approach used for the hydrological modelling part is described in Section 3.3 which covers model structures used, methodology for taking account of parameter uncertainty, and combination of results into distribution of flow factors.

\subsection{Sampling UKCP09 climate change factors}

One of the main challenges of this study was to develop a sampling strategy of UKCP09 changes that would allow a quick and robust assessment of climate change on river flows whilst still capturing the uncertainty in the UKCP09 projections. According to UKCP09 guidance at least 100 random samples are needed for impact assessments in order to maintain the probabilistic representativeness of the original sampled data. Such a sample size is however still too large for practical applications at the national-scale, and a strategy based on Latin Hypercube Sampling (LHS, McKay et al., 1979) has been adopted here to 
produce a smaller representative sample of the full UKCP09 dataset. LHS methods have been proved to be more efficient than random sampling (Stein, 1987) and they have previously been used successfully to assess the uncertainty of climate model parameters, notably for the development of UKCP09 projections themselves (Murphy et al., 2007), but also to assess the uncertainty in conceptual hydrological model parameters (Murphy et al., 2006; Shirmohammadi et al., 2008). This is however the first attempt at applying it to probabilistic climate change data. The approach chosen here is the optimal stratified LHS described by Stocki (2005).

Figure 4 illustrates the stratified LHS method as applied to the 10,000 UKCP09 factors. For simplicity the figure shows the selection process for nine samples and two dimensions corresponding to seasonal rainfall factors for winter (PDJF) and summer (PJJA). The 10,000 samples are split into nine columns each of which contain a 9 th of the samples, and then each column is again split evenly into 9 to give a total of 81 blocks, each of which contains roughly the same number of samples. LHS is used for selecting the blocks from which a sample is selected. From the blocks, a single UKCP09 sample is randomly selected to give 9 samples (in blue in Figure 4). By selecting the samples this way the samples are regularly spaced across the chosen climate variables to give the best representation of the overall distribution for the given sample size. Also, this method has an equal chance of selecting any given sample so therefore the samples are equally weighted. The stratified LHS has here been applied with eight dimensions corresponding to the seasonal changes in precipitation and temperature. The importance of different seasons tend to vary across the country between different types of catchments and preliminary experiments proved the importance of to considering all four seasons in this national-scale study. Moreover, the sample size has been chosen equal to 20 as a trade-off between accuracy and modelling efforts. This choice is further discussed in Section 5.2.

\subsection{Building daily climate time series for the 2020s}

The UKCP09 monthly change factors have been applied to historical catchment precipitation and temperature data to generate future daily time series, following in this way the delta change methodology used for previous nationalscale assessments (Arnell et al., 1997; Arnell, 2002).

The 11 HadRM3 monthly time series for the 2020s have been first spatially averaged over the two catchment case studies and then bias-corrected following the same framework as for the UKWIR06 projections, without the downscaling part (Vidal and Wade, 2008a). Indeed, RCM outputs have been shown to be biased with respect to observations over the historical period for example by Cloke et al. (2010) over the Medway@Teston (Thames river-basin region, 40003 in Figure 1).

The catchment-scale monthly time series derived from the 6 UKWIR06 projections and the 11 HadRM3 projections have been temporally downscaled to derive daily time series for the 2020s. For each calendar month, a month with the most similar amount of precipitation is selected from the observed catchment daily time series within the same season. The daily precipitation pattern 


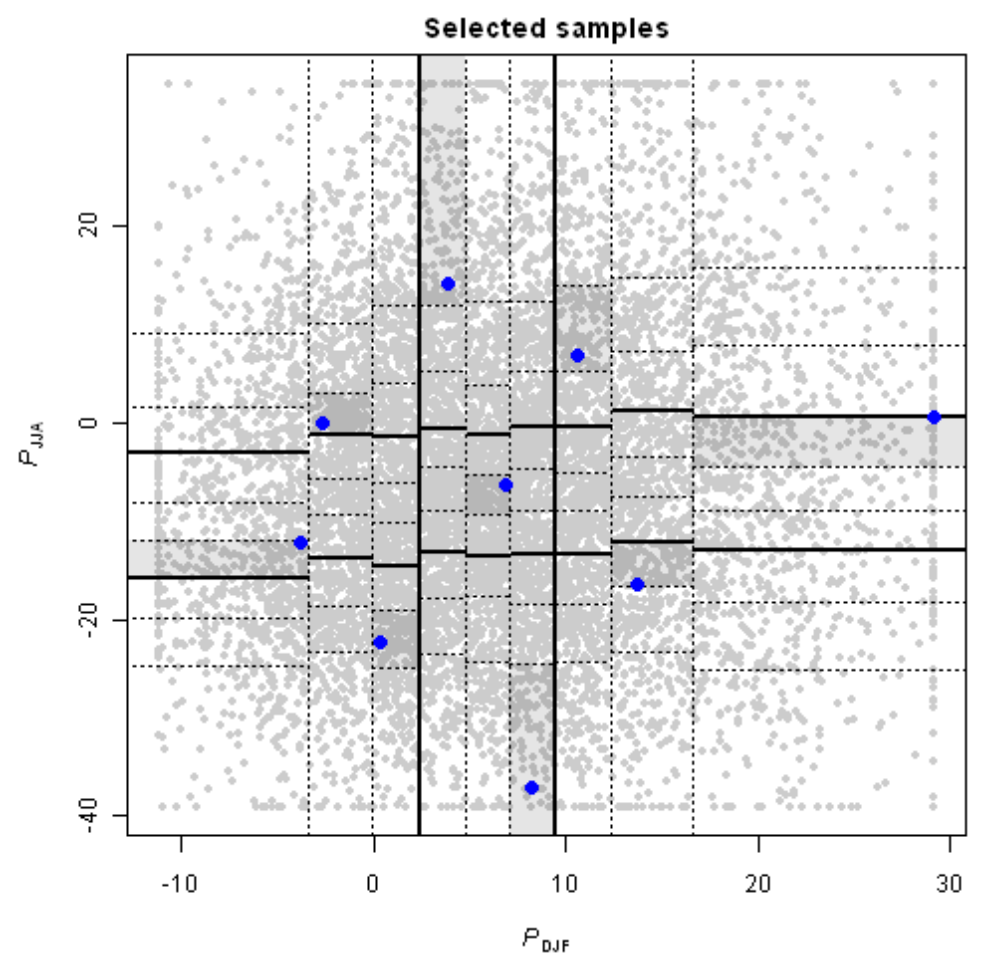

Figure 4: Illustration of an optimal LHS of size $\mathrm{n}=9$ in $\mathrm{d}=2$ dimensions (winter and summer precipitation change, in percent) used on the UKCP09 data for the Thames@Kingston catchment. LHS blocks are shaded and selected samples are shown in blue). 
of this particular month, rescaled to match the monthly amount, is then used as the daily pattern of the future GCM-derived time series. Future PET values have been calculated for the middle Julian day of each calendar month with the temperature-based formula. These were then interpolated thanks to a cubic spline algorithm to obtain daily time series, as done for computing historical PET (see Section 2.2).

\subsection{Hydrological modelling}

The hydrological modelling framework had been developed for the previous national-scale assessment and is detailed by Wade et al. (2006) and Vidal and Wade (2007a). The sets of hydrological calibrated models retained from the assessment have been reused for the present study. The main modelling steps are described in the following paragraphs.

Model structures. Two hydrological model structures were used: PDM, a lumped conceptual model (Senbeta et al., 1999) and Catchmod, a semi-distributed conceptual model (Wilby et al., 1994). The rationale behind using two model structures is that they provide an initial estimate of the uncertainty linked to the choice of a given model structure, following the approach of recent climate change impact studies (Kay et al., 2009; Wilby and Harris, 2006).

PDM (Probability Distributed Model) has been developed and used for more than 20 years (Moore, 1985, 2007), notably in climate change impact studies (Arnell et al., 1997; Prudhomme et al., 2003; Bell et al., 2007; Prudhomme and Davies, 2009a,b). This study made use of a version of PDM with 5 parameters described by Senbeta et al. (1999) and implemented by Wood (2005), using a linear reservoir for routing the fast and slow pathways.

Catchmod also has a long history and is currently being promoted as the standard hydrological model by the Environment Agency (WSAtkins, 2002). It has also been widely used in climate change impact assessments (Diaz-Nieto and Wilby, 2005; Wilby and Harris, 2006; New et al., 2007; Lopez et al., 2009; Manning et al., 2009). Catchmod works with different zones contributing to the output flow and corresponding to different paths, and this study makes use of models with 3 zones for fast, medium and slow paths with 5 parameters each. Within a given catchment, the area of each zone has been determined based on hydrogeological data from the Catchment Spatial Information module of the National River Flow Archive, following the rules detailed below and ensuring the consistency among all modelled catchments. As Irish catchments are not included in the NRFA database, the percentage area of each zone has been estimated from geological maps.

Each hydrogeological category has been attributed to a given flow path: fast ("Very low permeability"), slow ("High permeability (fissured and intergranular)", "Moderate permeability (fissured)") and medium (all other categories). Similarly, each drift category has been attributed to either the fast ("Landslip", "Lacustrine clays, stilts and sands", "Alluvium", "Boulder clay", "Morainic drifts") or the medium slow path (all other categories). the catchment area 
covered by drifts is first computed by adding areas of all drift categories. making the hypothesis that the remaining area is composed of the same percentage of hydrogeological categories as the whole catchment allows computing areas for each hydrogeological category without drifts. The area of each zone is then taken as the sum of areas from the corresponding flow path. A brief comparison of Baseflow Index (BFI) values with percentage areas for each zone of all catchments led to a positive correlation (0.68) with slow path areas, and a negative correlation (-0.59) with fast path areas (both significant at the $95 \%$ confidence level), along with virtually no correlation with medium path areas. This comparison thus supports the empirical rules derived made for allocating hydrogeological and drift categories to flow paths. It has to be noted that this consistent process over the UK led to model 5 catchments with only two zones (medium + slow), and 27 with only one zone ( 24 slow, 2 medium and 1 fast).

GLUE methodology. The GLUE (Generalized Likelihood Uncertainty Estimation) methodology (Beven and Binley, 1992) has been adopted in this study in order to assess the uncertainty in both model structure and model parameters. The GLUE methodology has been widely used over the last fifteen years for rainfall-runoff modelling over various locations (see for example Beven, 1993; Freer et al., 1996), and has recently been applied in climate change impact studies, notably in the UK (Cameron, 2006; Romanowicz, 2007; Cloke et al., 2010). Several studies are currently ongoing in order to improve this modelling framework (see for example Vrugt et al., 2009, and discussions), but for simplicity the commonly used methodology has been adopted here, with the choices described below.

PDM and Catchmod parameter ranges shown in Table 2 and Table 3 respectively have been derived from a literature review of studies using these models over various UK catchments (Wood, 2005; WSAtkins, 2002; Wilby, 2005). The ranges were chosen in order to encompass all physically plausible parameter values for a UK catchment, and thus allow a consistent approach for all 70 modelled catchments. For each catchment, 5000 parameter sets for each model structure were randomly sampled within the defined parameter ranges, thus providing 10,000 different catchment models. For simplicity uniform sampling was chosen over more complex and efficient sampling strategies (e.g., Markov Chain Monte-Carlo, Blasone et al., 2008), which is in line with other applications of the GLUE methodology (Beven, 2000; Cloke et al., 2010).

Table 2: PDM Parameter ranges.

\begin{tabular}{lrr}
\hline Parameter & Min & Max \\
\hline Maximum value of storage capacity depth $(\mathrm{mm})$ & 0 & 3000 \\
Slow tank constant (days) & 0.1 & 1000 \\
Fast tank constant (days) & 0 & 100 \\
Reflected power parameter & 0 & 20 \\
Parameter for groundwater flow & 0 & 0.02 \\
\hline
\end{tabular}


Table 3: Catchmod parameter ranges.

\begin{tabular}{|c|c|c|c|c|c|c|}
\hline \multirow[t]{2}{*}{ Parameter } & \multicolumn{2}{|c|}{ Fast } & \multicolumn{2}{|c|}{ Medium } & \multicolumn{2}{|c|}{ Slow } \\
\hline & Min & $\operatorname{Max}$ & Min & $\operatorname{Max}$ & Min & $\operatorname{Max}$ \\
\hline Slope of drying curve & 0.1 & 0.4 & 0.1 & 0.4 & 0.1 & 0.4 \\
\hline $\begin{array}{l}\text { Potential drying constant } \\
(\mathrm{mm})\end{array}$ & 0 & 150 & 0 & 250 & 0 & 250 \\
\hline Direct percolation (\%) & 0 & 100 & 0 & 100 & 0 & 100 \\
\hline $\begin{array}{l}\text { Time constant for linear reser- } \\
\text { voir (days) }\end{array}$ & 0 & 10 & 5 & 50 & 30 & 120 \\
\hline $\begin{array}{l}\text { Constant for non-linear reser- } \\
\text { voir }\left(\mathrm{m}^{3} \text {.days }\right)\end{array}$ & 0 & 500 & 500 & 10000 & 500 & 10000 \\
\hline
\end{tabular}

The GLUE methodology requires a likelihood measure to assess the performance of a given model. A number of such measures have been used within GLUE over the years (see, e.g., Choi and Beven, 2007). Romanowicz and Beven (2006) found that the choice of different measures influences the shape of the resulting distribution, but to a much lesser extent the uncertainty bands for the predictions. The likelihood measure chosen for this study was based on the Nash-Sutcliffe Efficiency (NSE, Nash and Sutcliffe, 1970) applied to the logarithm of flows. This particular measure reduces the influence of high flows and gives more weight to low to median flows (Krause et al., 2005). Models with a daily NSE > 0.5 over the whole 1961-1990 baseline period were considered to be behavioural and retained for subsequent analysis. This threshold and the associated uncertainty will be discussed in Section 5 .

The number of behavioural models and NSE for the best-fit model, using either the PDM or Catchmod structure, can be found in Figure 5. It shows that behavioural models are easier to find within the parameter space with Catchmod structure, due to the higher number of parameters. Nine catchments, mainly located in the Thames and Anglian regions, could not be modelled with the PDM structure. As already noted by Young (2002), the PDM structure appears not to be adapted to catchments with low standard annual rainfall. A detailed examination of the two catchments that could not be modelled with the Catchmod structure suggests that the constraints imposed to the areas attributed to each flow path are too strong in these particular cases.

Deriving distributions of flow factors. For a given catchment, each behavioural model from either model structures has first been run under the observed 19611900 climate to derive baseline monthly mean flows as well as the corresponding likelihood measure. The same hydrological model has then been forced by one of the future climate projections described in Section 3.2 to compute future monthly flows. Monthly flow factors could then be computed for this particular hydrological model and were attributed the present-day likelihood measure. This procedure has been applied to all behavioural models, regardless of their model structures, leading to weighted distributions of monthly flow factors for one future projection. The individual climate projections within a data set 

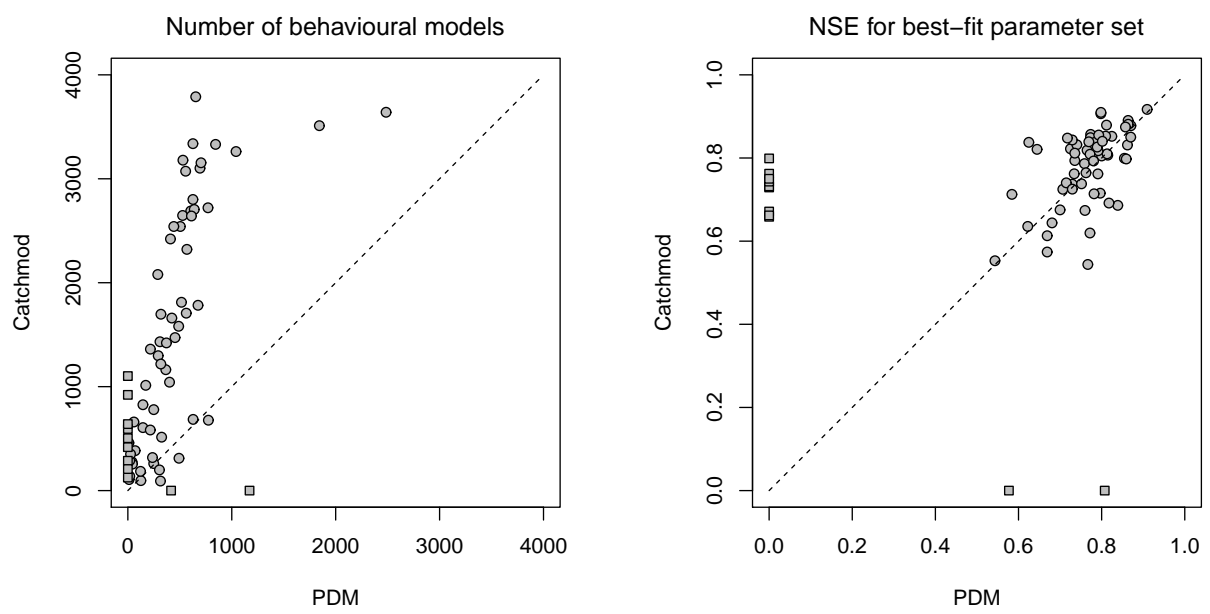

Figure 5: Number of behavioural models for all 70 catchments (left) and NSE for best-fit parameter set (right), for PDM and Catchmod model structure. Squares denote catchments where no behavioural model could be found from one or the other structure.

(UKCP09, UKWIR06 or HadRM3) have finally been combined by applying equal weights to each member.

\section{Results}

\subsection{Changes in precipitation and potential evapotranspiration}

This section presents intermediate results in terms of climate for the 2020s as derived from the three climate data sets through the sampling of initial distributions (for UKCP09), the aggregation at the catchment scale, and the calculation of PET.

Sampled UKCP09 changes at the river-basin scale. Figure 6 shows the central estimates of changes in precipitation derived from the sampled UKCP09 factors at the river-basin scale. The general pattern indicates an increase in winter precipitation mainly across the north-western part of the UK, together with a widespread decrease in summer precipitation. Similar features were also found by Vidal and Wade (2008a) in the UKWIR06 projections although impacts in the southwest in the summer were smaller. The UKCP09 factors also indicate larger increases in rainfall in the winter in the west of the country and the impacts in northern Ireland are larger compared to the UKWIR06 projections.

Figure 7 shows the central estimates of changes in PET derived from sampled UKCP09 temperature factors and the temperature-based formula. The maps show an increase in PET across the country with the largest changes occurring in the winter months and larger changes in the northern part of the UK. The increase in PET is a reflection of warming of up to 2 percent across the country. Changes in summer mean temperatures are greatest in parts of southern 


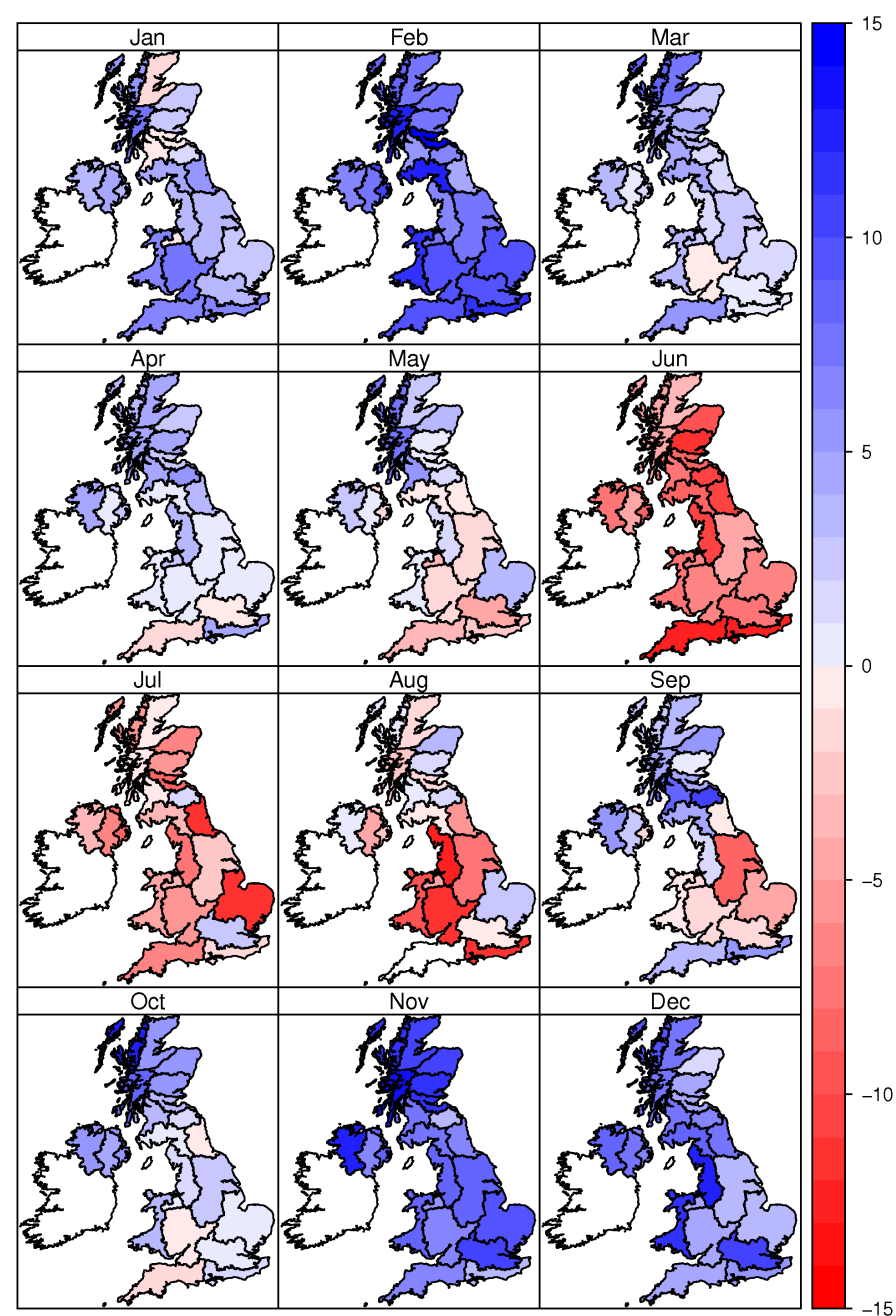

Figure 6: Maps of central estimates of monthly precipitation changes derived from the sampled UKCP09 probabilistic changes over river-basin regions. 


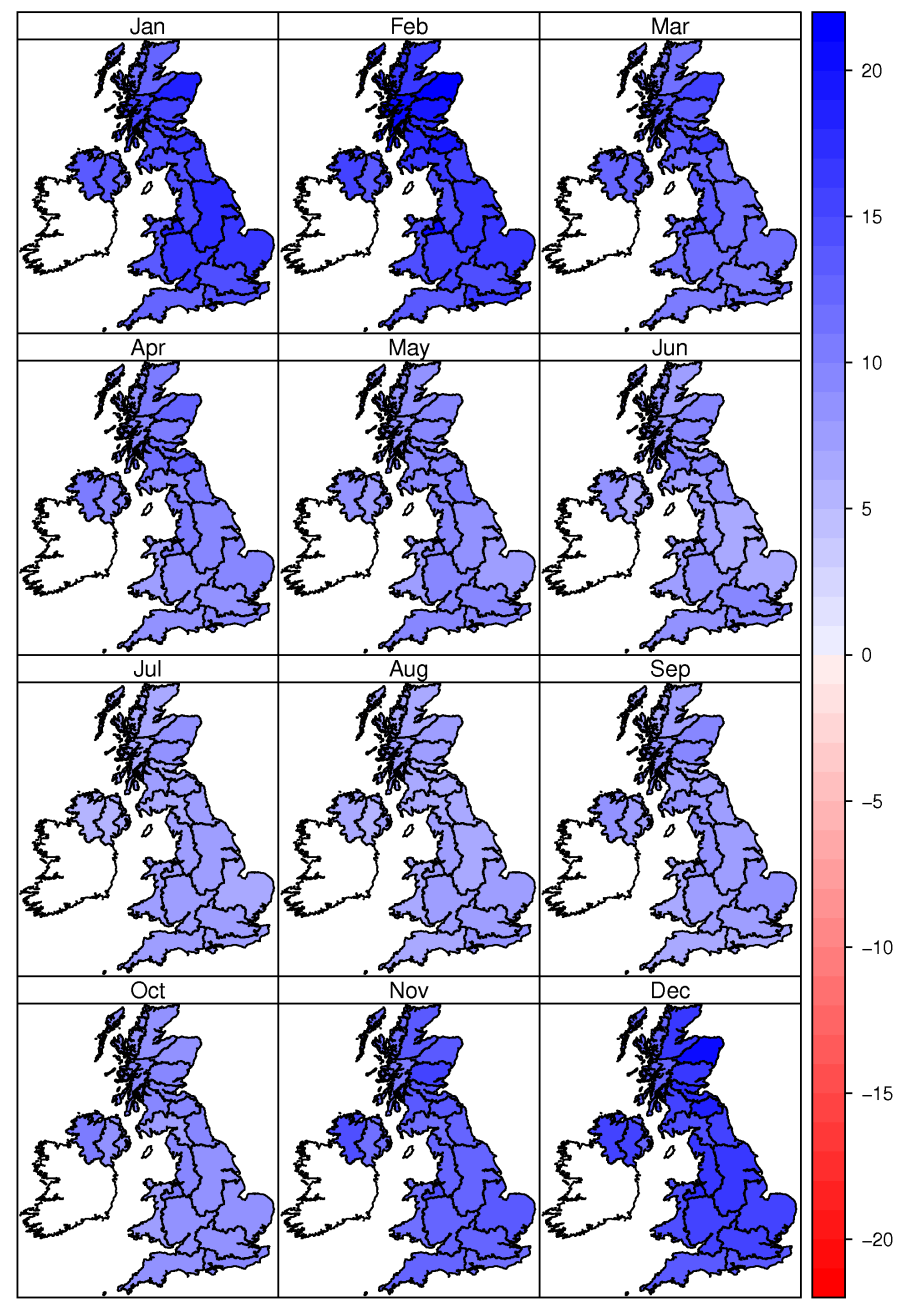

Figure 7: As for Figure 5, but for PET.

England (up to $4.2 \mathrm{C}$ (2.2 to $6.8 \mathrm{C}$ )) and least in the Scottish islands (just over $2.5 \mathrm{C}(1.2$ to $4.1 \mathrm{C}))$. Whilst temperature increases are larger in southern England this results in smaller relative changes in PET than in the north where the absolute baseline PET is much lower. Similar changes in PET were observed in the UKWIR06 projections.

Catchment case studies. Figure 8 compares the precipitation and PET annual cycles of changes for the Ribble@Arnford, as given by the individual climate projections from the three different climate scenario data sets described in Section 2.3. The visible annual cycle of precipitation changes already noted in 

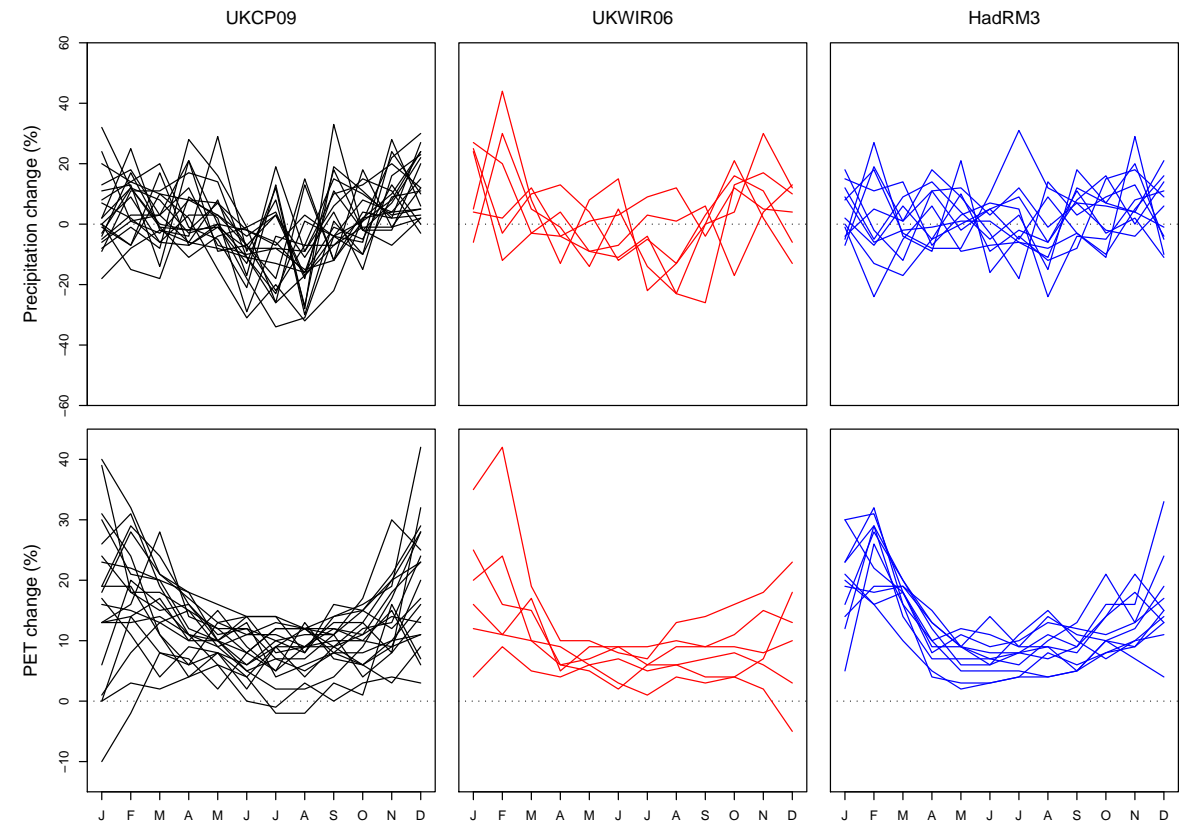

Figure 8: Annual cycle of changes in precipitation (top row) and PET (bottom row) for the Ribble@Arnford. Left: 20-member sampled subset of UKCP09 changes; middle: changes from the 6 individual UKWIR06 projections; right: changes from the 11-member ensemble of bias-corrected regional projections.

Figure 6 can be seen again in the top-left plot, with an increase in winter precipitation and a decrease in summer precipitation. A similar cycle was also observed in the UKWIR06 projections (Vidal and Wade, 2008a), but can hardly be identified in the 11-member ensemble of HadRM3 projections. This last observation corroborates the fact that this ensemble of regional projections does not include the full range of uncertainty available through the UKCP09 projections, as HadCM3 is the only driving GCM for this ensemble. A remarkable feature shown by Figure 8 is a very similar dispersion of the UKCP09 and UKWIR06 ensembles. Changes in PET indicate a much more pronounced annual cycle, with nearly all projections showing an increase in PET all year round, but with much more dispersion in winter than in summer for all 3 sets. Once again, the HadRM3 ensemble stands out from the two other sets by showing a consistently large increase in winter PET.

Annual cycles of changes in precipitation and PET for the Thames@Kingston catchment are shown in Figure 9. Conclusions similar to the Ribble@Arnford can be drawn from these plots, with one major difference: the dispersion of UKCP09 (and HadRM3) precipitation changes for some months in winter and summer are much higher than for the Ribble@Arnford, with some members showing increases beyond $40 \%$. The larger UKCP09 uncertainty bands in the south-east of England compared to the north-west of the British Isles have 

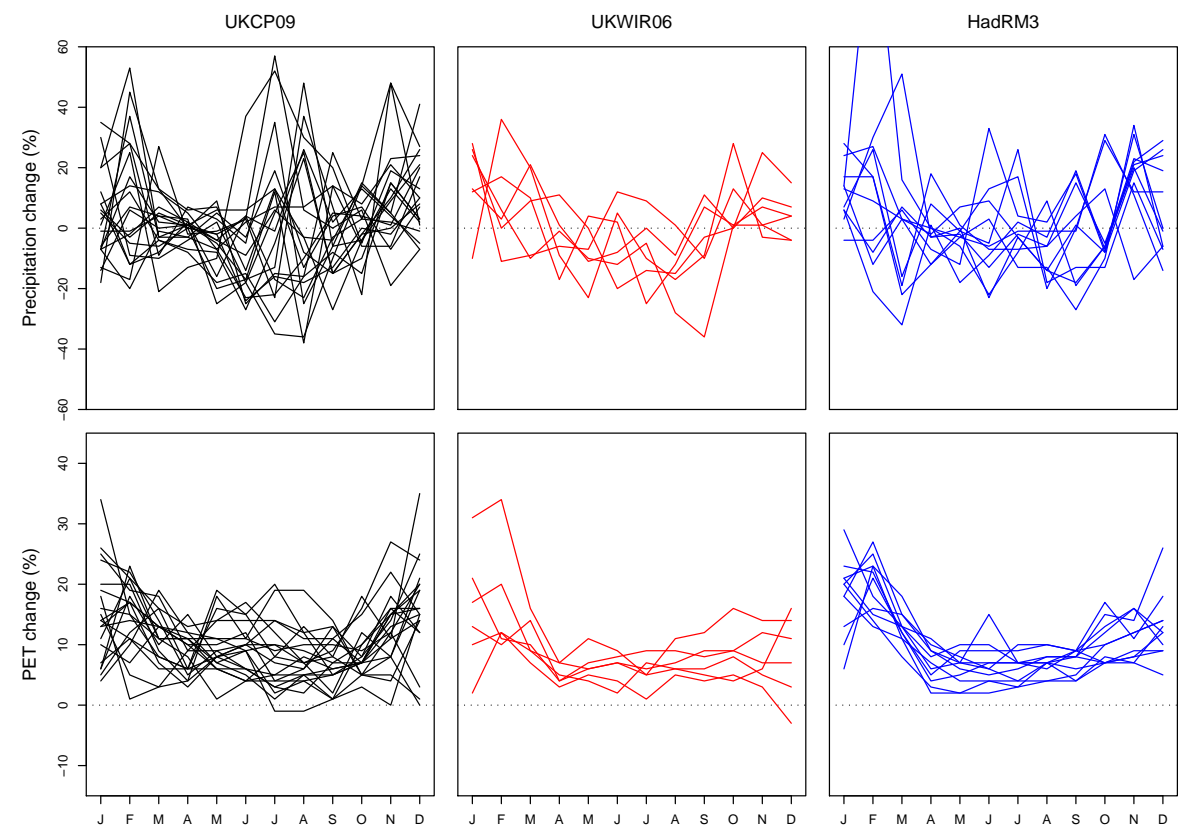

Figure 9: As for Figure 8, but for the Thames@Kingston.

already been shown by Murphy et al. (2009, table 4.5 and Figure 4.11).

\subsection{River flow changes derived from UKCP09 climate changes}

Changes in mean annual flow. Figure 10 shows changes in annual flow derived from UKCP09 climate changes presented as violin plots. Individual results from the ensemble of hydrological models multiplied by the number of UKCP09 climate change subsets have been used to fit continuous probability density functions-weighted with the associated likelihood measures-using kernel density estimates with gaussian kernel (Wilks, 2006, p. 35).

Firstly, the map shows a relatively large uncertainty in projections, with most catchments exhibiting changes with a non-null probability ranging between $-10 \%$ and $+10 \%$. The distributions shown in Figure 10 gathers two properties of the climate change factors used: first, their range is conditioned for a large part on the initial UKCP09 change factors distributions, as exemplified in Figure 2. Second, the multi-modal characteristics of the distributions for most catchments is linked with the sampling step that provides only a discrete subset of factors. It thus confirms that very low and very high percentiles of changes have to be treated with caution. Figure 10 also shows that this climate uncertainty can be intensified through the hydrological processes, as it appears to be the case in the pervious catchments of south-east England. Median changes in annual flow appear to be slightly positive in Scotland and Northern Ireland, but clearly 


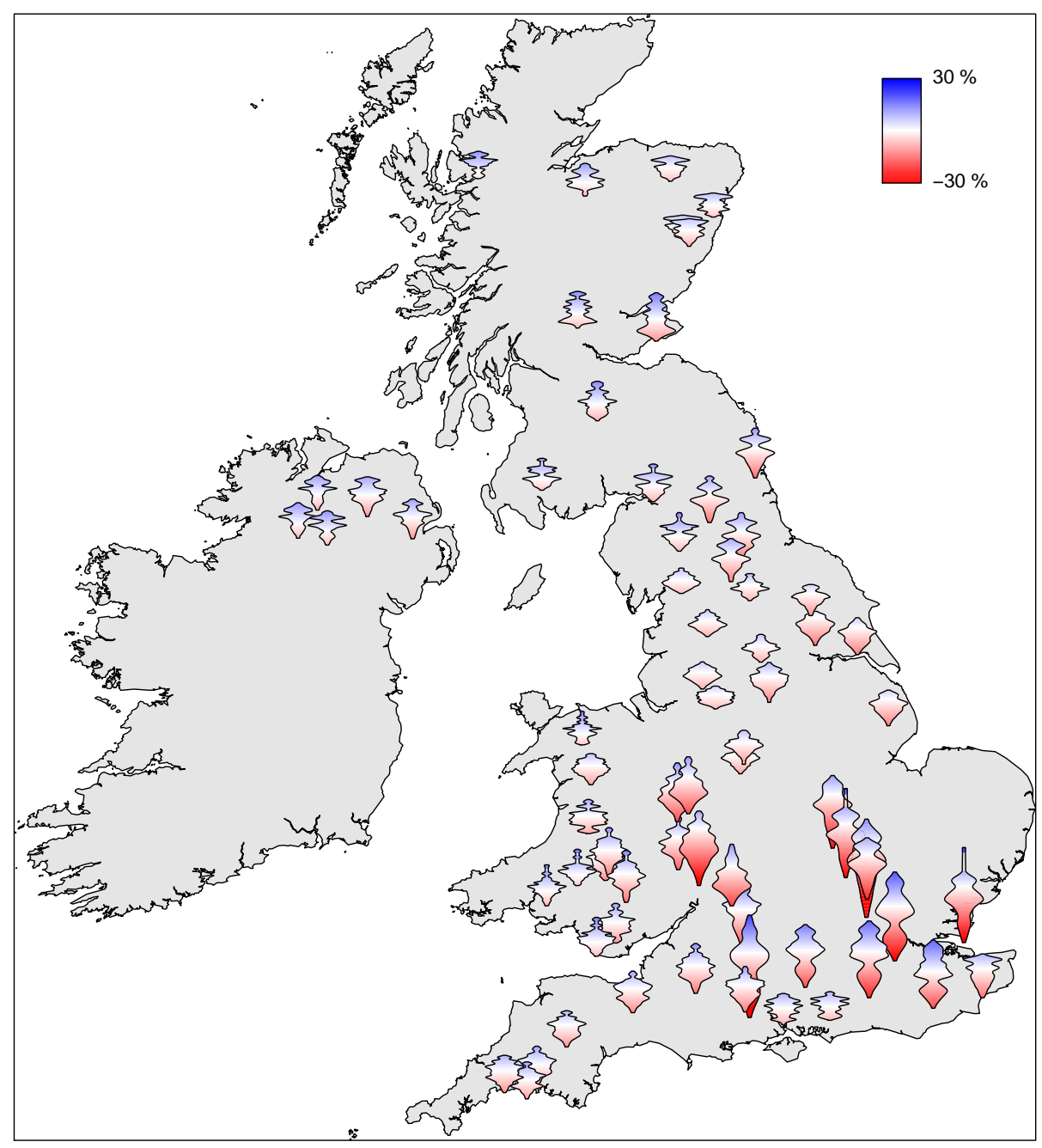

Figure 10: Distributions of changes in mean annual flow (\%) for the 2020s for the 70 modelled catchments with the sampled UKCP09 climate change forcings. Blue and red colors in the violin plots indicate the position of the distribution with respect to zero (no change).

negative for the rest of the UK. This representation however hides the intraannual variations that are examined below.

Changes in mean monthly flows. Figure 11 plots the first, second and third quartiles of monthly changes in river flow. These percentiles have been chosen to give a robust measure of the dispersion of the distributions whilst avoiding potential discrepancies on the extremes caused by the sampling of climate change distributions (see Section 5.2).

Results in terms of central estimates (middle column) show a marked sea- 
sonal cycle, with large reductions in summer flows. A geographical split between the western and northern mountainous part of the UK (Scotland, Northern Ireland, North-West England, Wales and Cornwall) and the rest of the UK is also clearly visible: a small increase in winter flows (from November to March) can be noted over this western part, whereas in all other catchments, a decrease in river flows is visible all year round. This is a direct consequence of the geographical split observed in winter precipitation changes in the sampled UKCP09 data, which occurs over mainly mountainous and impervious catchments (Bower et al., 2004).

Looking at the third quartile maps (right), it can be seen that most of the catchments feature negative or very slightly positive values of summer flow changes. This shows that a relatively high probability can be assigned to a decline in summer flows. In the UK this period unfortunately corresponds to the low-flow period when the supply-demand balance is tight, especially in southeast England. The first quartile maps (left) show that the largest flow decrease can be seen in the Thames, Anglian and Severn river-basin regions, with values below $-10 \%$ all year round and much lower in summer.

\subsection{Comparison with river flow factors using other climate projections}

At the national scale. Figure 12 shows maps of central estimates as well as first and third quartile of the distribution of changes in monthly river flows as derived from the hydrological model ensembles forced by the six UKWIR06 projections. It synthesizes the scenarios developed for the previous national-scale assessment (Vidal and Wade, 2007a) which were incorporated into the water resources planning guideline by the Environment Agency (2008) as a framework for water companies to follow in developing and presenting their water resources plans. Compared with Figure 11 showing flow factors using UKCP09 the general features - overall decrease of central estimates, geographical split, etc. - were already present in UKWIR06 flow factors, but some differences can be spotted. From November to March, the whole UKWIR06 distribution seems to be shifted towards higher flow factor values, leading to a potentially higher increase in soil moisture and recharge to groundwater aquifers. Conversely the upper quartile of distributions for July to September shows lower and negative values over most of England, suggesting higher confidence in the reduction of summer low-flows than in the UKCP09 data set. The range of uncertainty is generally higher in the UKCP09 projections in the summer which was also reflected in the climate factors.

Catchment case studies. Figure 13 and 14 present detailed information about the change in the annual hydrological cycle for the two catchment case studies. These include plots of the 1961-1990 baseline period mean flows for each month together with an estimate of the corresponding natural variability. The interval of natural variability has been computed as the $90 \%$ level bootstrap confidence interval derived from the observed monthly flow time series. They also show the monthly distributions of river flow derived from the three future climate data sets described in Section 2.3. River flow factors derived from the overall 


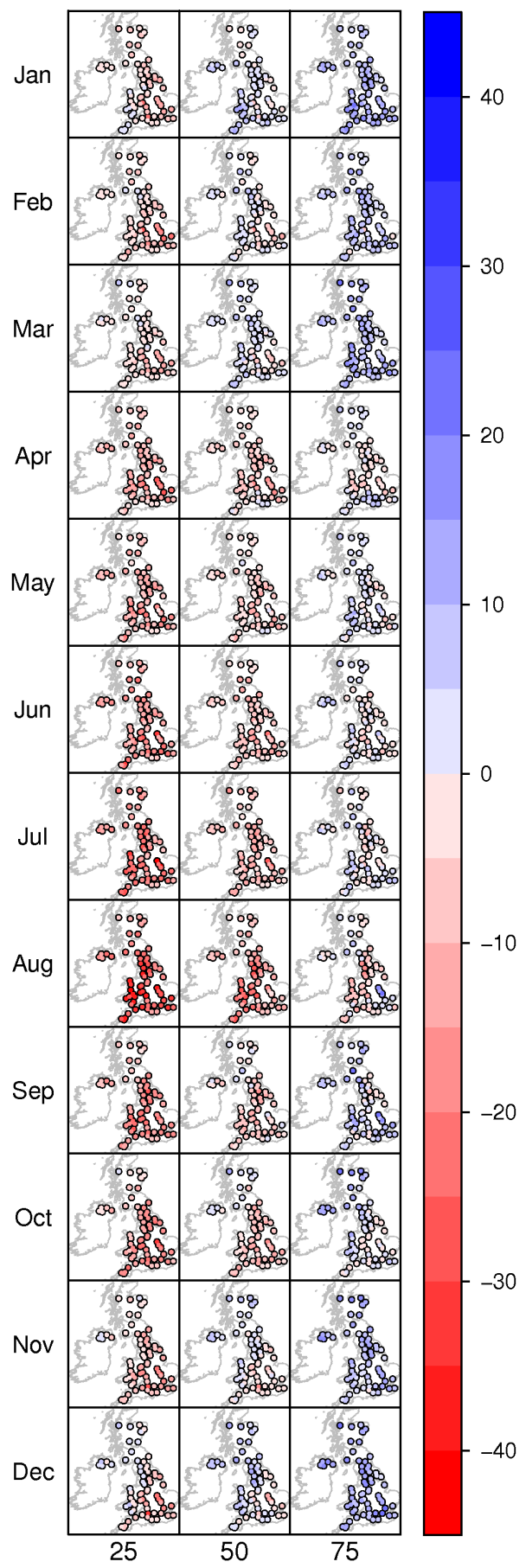

Figure 11: From left to right: first, second and third quartiles of monthly changes in river flow (\%) for the 2020s for the 70 modelled catchments with the sampled UKCP09 climate change forcings. 


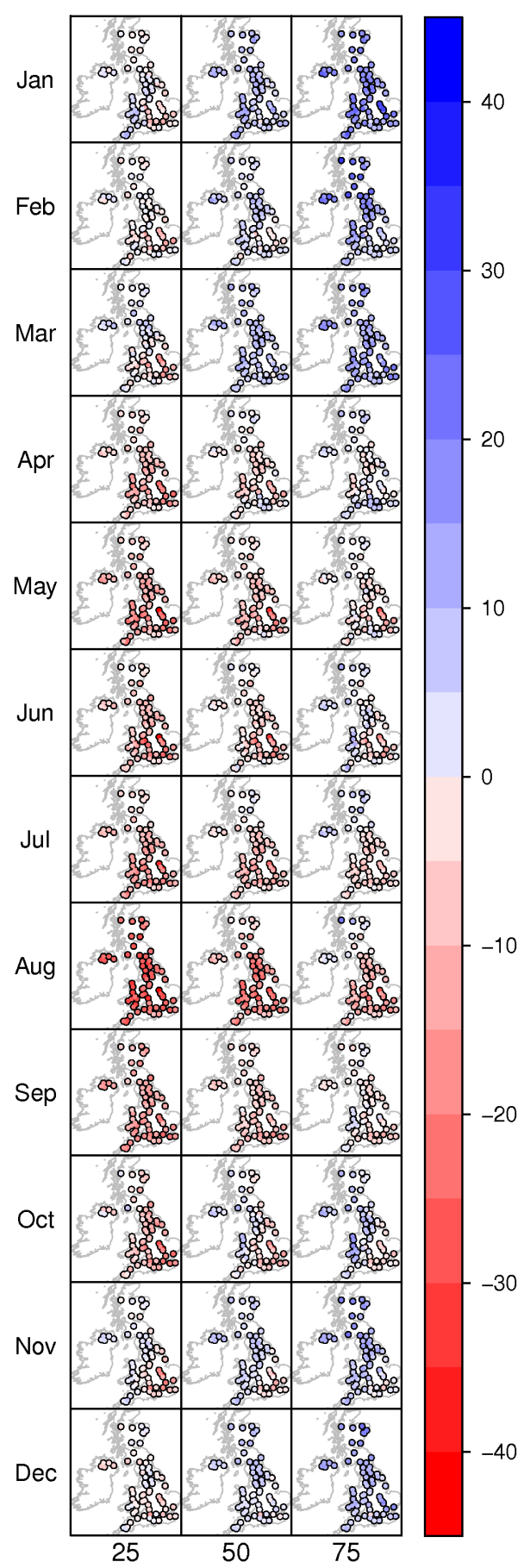

Figure 12: As for Figure 11, but with UKWIR06 climate projections forcings. 


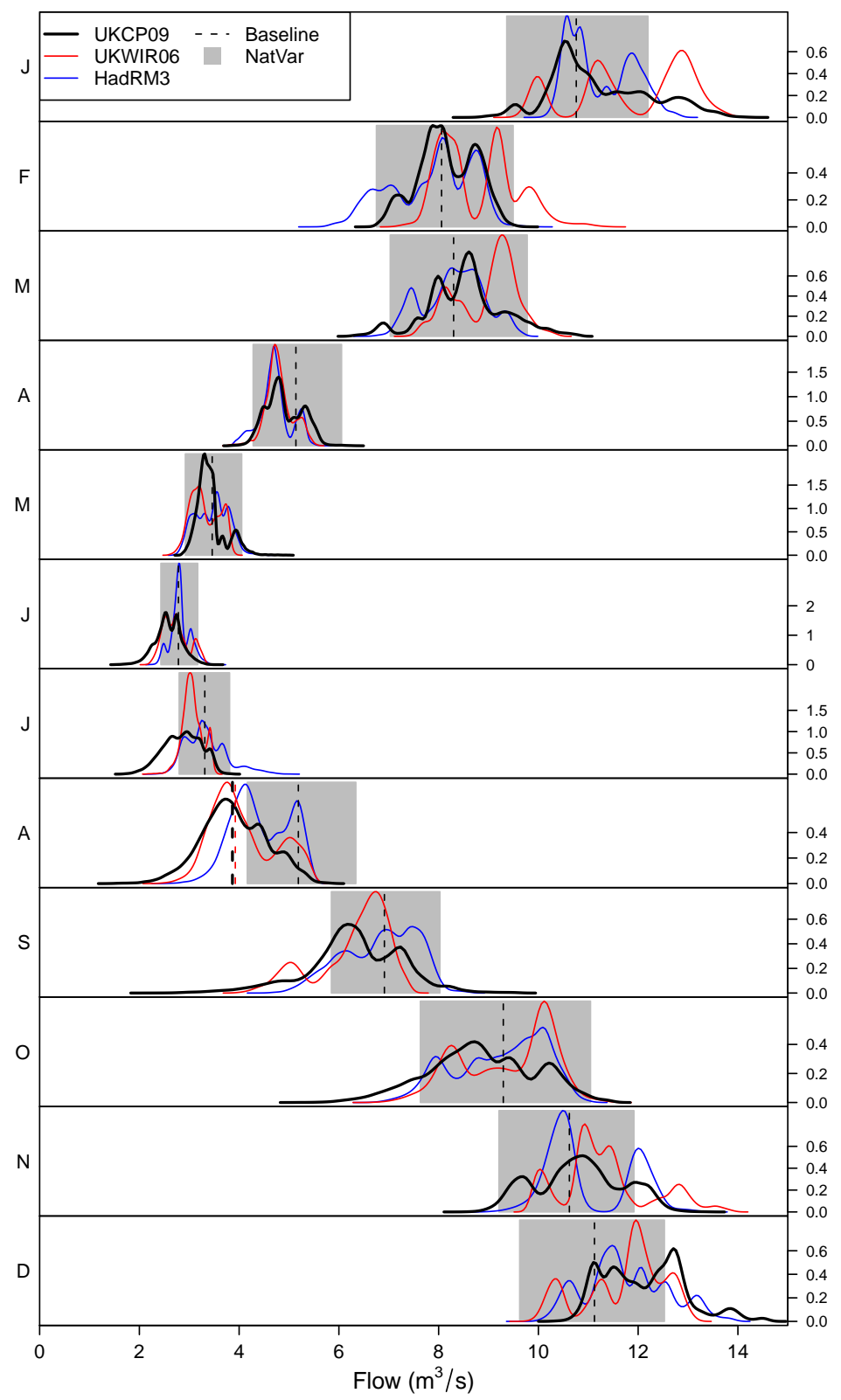

Figure 13: Mean monthly flow for the Ribble@Arnford for the 1961-1990 baseline period and for the 2020s as derived from the three future climate datasets. Grey bands show the 90\% interval of 1961-1990 natural variability (see text for details). Median values of future distributions are plotted as dotted vertical lines only if they fall outside of the range of natural variability. Note the different $y$-scales for each month. 


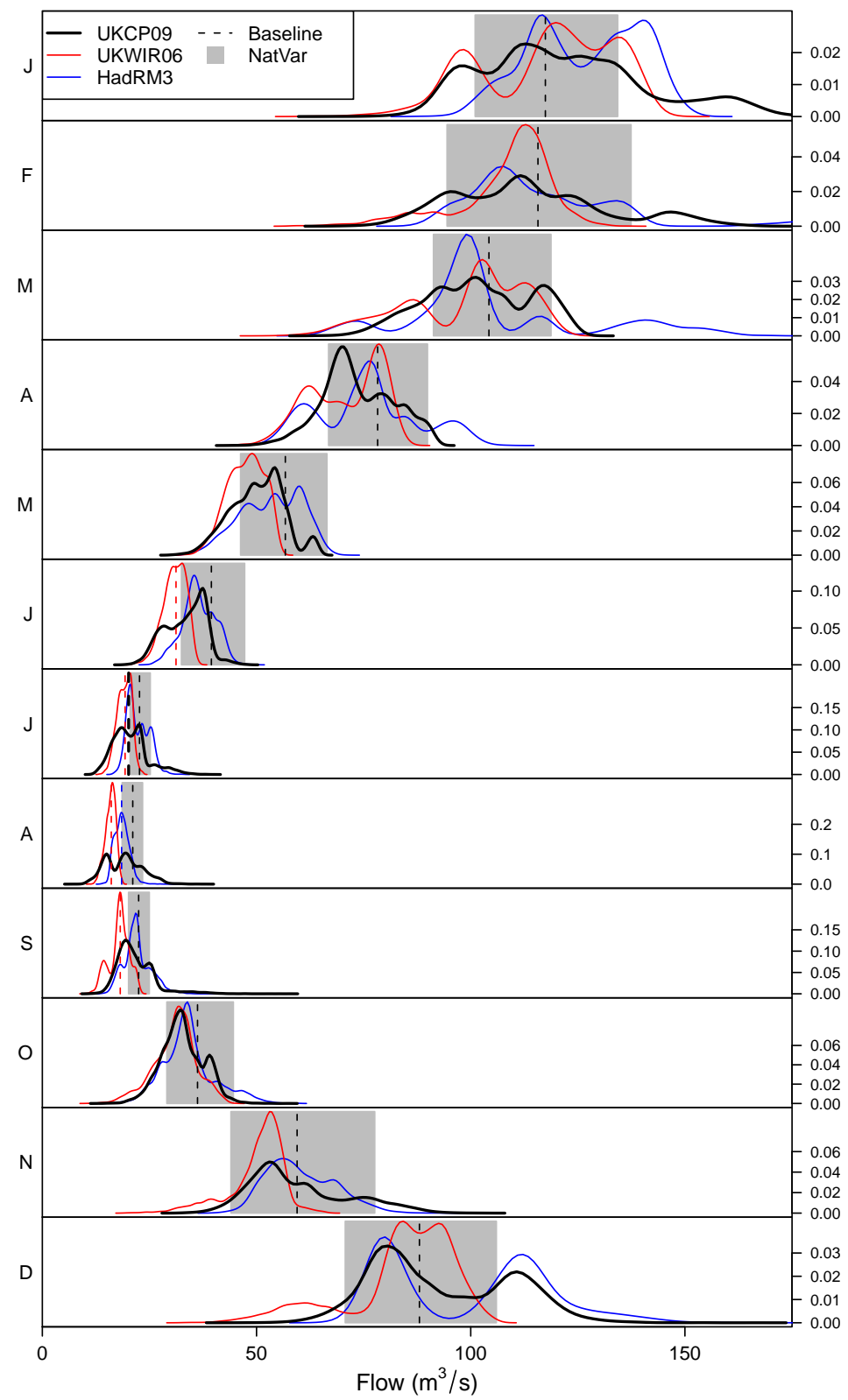

Figure 14: As for Figure 12, but for the Thames@Kingston. 
method detailed in Section 3 have been applied to the baseline mean monthly flows in order to compute the corresponding values in cubic meters per second. Continuous probability density functions have been fitted to these values using kernel density estimates.

Figure 13 shows the baseline and future flow regimes for the Ribble@Arnford. Future mean monthly flows are shown as distributions which combine the uncertainty due to the climate forcings (cf. Section 2.3) and the uncertainty due to the hydrological modelling (cf. Section 3.3). The first thing to notice in Figure 13 is the multi-modal characteristic of most distributions, which derives from the discrete property of all three future climate forcing ensembles. The LHS sampling performed on UKCP09 climate change distributions helped to reduce such characteristic with respect to the other two data sets, in spite of the relatively low ensemble size. The important feature shown by this plot is the fact that most distributions are largely included in the range of natural variability as defined above. Indeed, median values of future distributions fall outside this range only in August, when future flows are projected to decrease by around 25\% according to both UKCP09 and UKWIR06 projections. Moreover, despite the variation of distribution shapes between these two data sets, central estimates and dispersion are of a similar order, which reinforces the confidence in the results for this catchment. It should also be noted that the distributions derived from the HadRM3 ensemble also exhibit a very different shape from the whole UKCP09 distributions.

Looking at results for the Thames@Kingston in Figure 14, the dispersion of distributions in monthly flows appears to be larger than the range of natural variability for UKCP09 and HadRM3 data sets compared to the Ribble@Arnford. The main reason may be found in the larger dispersion - noted in Figure 9 - in winter and summer precipitation within the corresponding climate change data sets noted. Another major difference to the Ribble catchment is the projected decrease of summer flows according to the UKWIR06 scenarios, with median values falling below the lower part of the natural variability range from June to September. Similar cases can also be found for the other two climate data sets, but only in July for UKCP09, and in August for the HadRM3 ensemble. The projected flows derived from UKCP09 climate changes thus appear more conservative than the previous assessment, as a consequence of the under-dispersed summer distributions already noted in Section 4.3. This probably results from an insufficient spread in climate forcings in UKWIR06, composed of individual projections from only 6 GCMs.

\section{Analysis of uncertainties}

The paragraphs below propose an analysis of (1) the source of uncertainties in UKCP09-derived river flow changes and (2) the uncertainty related to the LHS sampling adopted for dealing with UKCP09 probabilistic information. 


\subsection{Decomposition of uncertainty between climate and hydrology}

The distributions of changes shown in Figure 11, 13 and 14 combine two types of uncertainty: (1) the uncertainty in UKCP09 climate projections and (2) the uncertainty of the modelled hydrological response to each projection. An analysis of variance of monthly changes in river flow has been performed in order to evaluate the amount of uncertainty due to each type. For a given catchment $c$ and a given month $m$, let $F_{p, h}$ be the factor of change in $\%$ given by the hydrological model $h$ under the climate projection $p$. Let note:

$$
\bar{F}=\frac{1}{20 \cdot n_{c}} \sum_{p=1}^{20} \sum_{h=1}^{n_{c}} F_{p, h}
$$

the mean of all flow factors where $n_{c}$ is the number of behavioural models retained, 20 is the number of sampled climate projections, and:

$$
\overline{F_{p}}=\frac{1}{n_{c}} \sum_{h=1}^{n_{c}} F_{p, h}
$$

the mean of factors derived from a single projection $p$. One can write the total sum of squares TSS of factors for this catchment and this particular month:

$$
T S S=\sum_{p=1}^{20} \sum_{h=1}^{n_{c}}\left(F_{p, h}-\bar{F}\right)^{2}
$$

TSS can be furthermore written as (von Storch and Zwiers, 1999, chap. 9):

$$
T S S=B S S+W S S
$$

where:

$$
B S S=\frac{1}{n_{c}} \sum_{p=1}^{20}\left(\overline{F_{p}}-\bar{F}\right)^{2}
$$

is the between-climate-projections sum of squares and:

$$
W S S=\sum_{p=1}^{20} \sum_{h=1}^{n_{c}}\left(F_{p, h}-\bar{F}\right)^{2}
$$

is the within-climate-projection sum of squares. One can then calculate the proportion of variance due to climate projections, with an unbiased estimator of the numerator (von Storch and Zwiers, 1999, chap. 9):

$$
R_{a}^{2}=\frac{B S S-\frac{20-1}{20 \cdot\left(n_{c}-1\right)} W S S}{T S S}
$$

Figure 15 shows the distribution of $R_{a}^{2}$ across all catchments for each month of the year. This proportion of variance can be seen as the part of uncertainty 


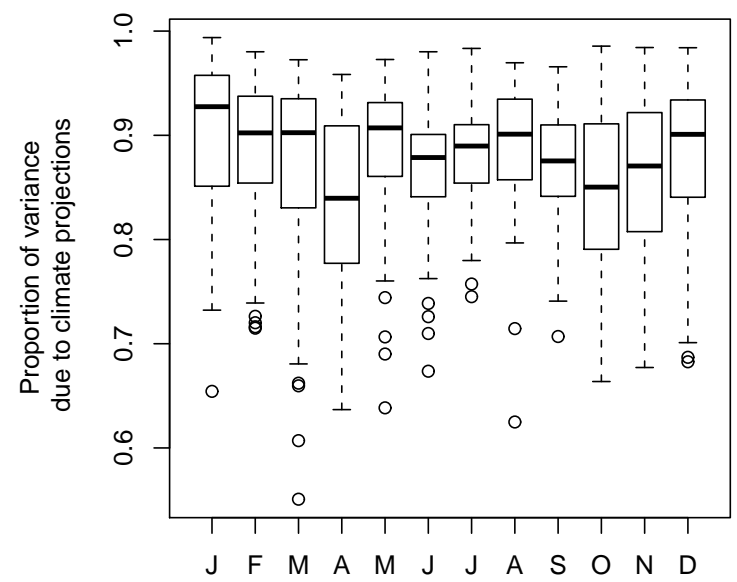

Figure 15: Proportion of variance of monthly changes in river flow due to climate projections for all 70 modelled catchments.

due to the spread of climate projections. The uncertainty in climate projections appears to dominate systematically over the uncertainty in hydrological modelling response, with very high median values for all months. The spread of values across the 70 modelled catchments, represented by box plots in Figure 15, shows a spatial diversity of this uncertainty attribution that is higher in winter. This results from the north-west/south-east differential spread of changes in winter precipitation already discussed in Section 4.1. The uncertainty in hydrological modelling response is thus very small compared to the uncertainty in climate projections, even with the relatively low threshold of the likelihood measure adopted here (see Section 3.3) that led to retain a relatively large variety of hydrological model parameter sets. It has however to be noted that this decomposition of uncertainty holds for changes in monthly flows, but may be different for example for low-flow indices likes the Q95 (flow exceeded $95 \%$ of the time).

\subsection{Effect of sampling size}

Experiments were conducted on applying stratified LHS with different sample sizes for the two catchment case studies. Sampled UKCP09 changes were then propagated through hydrological models in order to see the impact of sampling on monthly river flow changes. Figure 16 presents some results for the Thames@Kingston catchment, with eight dimensions (seasonal changes in precipitation and mean temperature) and different sample sizes. It shows that a sampling of size 20 (chosen in this study) captures most of the uncertainty for the three quartiles, as no significant improvement is achieved for sample sizes above 100. Note that the convergence to values above 0 is due to the rounding of factors preliminary to the analysis. Note also that results for small sample sizes are associated with some sampling uncertainty as only one set of samples is shown here. Figure 16 also shows that more extreme quantiles tend to be more 

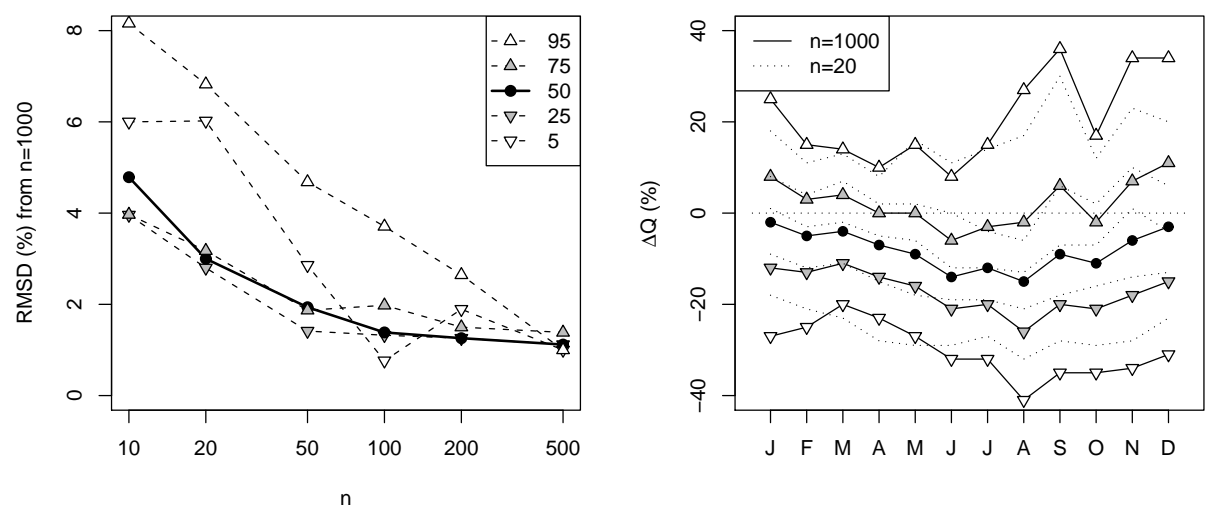

Figure 16: LHS of seasonal changes in precipitation and temperature: Effect of sample size $\mathrm{n}$ on changes in river flows for the Thames@Kingston. Left: root mean square deviation of monthly changes (in percent) from the experiment with $\mathrm{n}=1000$ for different quantiles of the distribution $(5,25,50,75$ and 95). Right: annual cycles of flow changes for $\mathrm{n}=20$ and $\mathrm{n}=$ 1000 , for the same quantiles.

dependent on sample size and that using twenty samples introduces noticeable uncertainty in more extreme quantiles. This strongly suggests that the tails of distributions in river flow changes should be treated with caution.

\section{Assumptions and related limitations}

Formulation of potential evapotranspiration. As shown by Ekström et al. (2007), Kay and Davies (2008) and Kingston et al. (2009), potential evaporation is a critical source of uncertainty for assessing hydrological impacts, and different calculation methods may lead to different estimates of changes in PET. Kingston et al. (2009) tested 6 different formulations of PET based on inputs from 5 different GCMs. They found potentially large differences of latitudinally averaged changes in PET between the different formulations, as a response of a global $2^{\circ} \mathrm{C}$ temperature rise. Kay and Davies (2008) compared the temperature-based Oudin formula used here Oudin et al. (2005b) with a version of the PenmanMonteith formula, with inputs from 5 GCMs and 8 RCMs over the UK, in both present and future climate. They first found that, with climate model input over the 1961-1990 period, using the Oudin formula gives a better fit than the more complex Penman-Monteith formula with respect to the MORECS (Meteorological Office Rainfall and Evaporation Calculation System) data (Hough and Jones, 1997), the common reference PET data set for the UK. They also found that both methods lead to quite different changes in PET for the end of the century under the A2 emissions scenario, with no method giving systematically higher changes than the other, depending on the month of the year and the location. Ekström et al. (2007) compared the temperature-based Blaney-Criddle and Penman-Monteith formulas for a case study in North-West England, with inputs from the HadRM3H RCM in both present and future climates. They 
found that the Blaney-Criddle formulation lead to (1) a better fit with PET calculated with Penman-Monteith formula with observed input data, and (2) much smaller changes that the Penman-Monteith formula.

According to Kay and Davies (2008) and Ekström et al. (2007), such surprising results may originate from the reliability of other GCM- or RCM-derived variables than temperature used in the data-intensive Penman-Monteith formulation. Based on a comparison study over deciduous forests, Shaw and Riha (2011) suggest that using temperature-based formulas may lead to an overestimation of water deficits. Different and somewhat complementary issues are moreover related to the choice of using or not an offline PET formulation. Taking account explicitly of the effect of increasing $\mathrm{CO} 2$ may indeed for lessen PET increase, due to a modified transpiration of plants as well as a changed canopy resistance (see for example Betts et al., 2007; Bell et al., 2011).

From the studies referenced above, it can be seen that the issue of PET formulation for climate change impact assessments is currently far from settled. Ideally, one would systematically use different formulations to take account of the associated uncertainty. Only the Oudin et al. (2005b) formula has been used here for two main reasons: first, the use of different formulations would have considerably increased the computation burden resulting from the multiplication of catchments, climate projections, hydrological model structure and hydrological model parameter sets. Second, this study aimed at examining the differences with the previous national-scale assessment due solely to different climate projections. The entire hydrological modelling approach has therefore been kept as close as possible to the one developed by Vidal and Wade (2007a). In particular, choosing another formulation of PET would have inevitably changed the sets of behavioural models for each catchment, making uncertainty assessments and comparisons rather problematic.

In order to assess the confidence in hydrological results obtained here as a consequence of this particular choice of PET formulation, changes in PET presented in Section 4.1 are qualitatively compared below to other studies having implemented other types of PET calculation over the whole of UK and for the two catchment case studies. One of the main UK-wide results in PET changes presented in Figure 7 is a north-west to south-east gradient, with higher increases in Scotland. Kay and Davies (2008) also found this gradient in maps of mean annual PET changes derived from an ensemble of GCM and RCM projections for the 2080s with both the Penman-Monteith equation and the temperature-based formulation proposed by Oudin et al. (2005a). Ekström et al. (2007) found a north-south gradient over the UK when applying a PenmanMonteith formula to HadRM3 outputs, even if absolute change values have been considered unreasonably high by the authors.

At the catchment scale, more detailed comparisons can be drawn. For the Ribble@Arnford, the larger uncertainty in winter relative changes shown in Figure 8, also found by Kay and Davies (2008) with both Penman-Monteith and temperature-based formulations, ensues from the much smaller absolute values of PET in the winter months compared to summer months. Median values of PET changes are moreover consistent with those found by Fowler et al. (2008) 
for a nearby catchment, the Eden@TempleSowerby. Indeed, using a Penman formulation embedded in a stochastic weather generator (Kilsby et al., 2007) conditioned by $13 \mathrm{RCM}$ projections from the PRUDENCE project (Christensen and Christensen, 2007), they found a similar annual cycle and changes about twice higher than the one shown in Figure 8, for a more distant period, namely the 2050s. For the Thames@Kingston, changes in PET compares reasonably well with values obtained by Wilby and Harris (2006) on this specific catchment for the same period. The confidence in the results from the present study is increased by the fact that a completely different scheme for computing PET was used, based on statistical relationships between large-scale predictors and observed PET from the MORECS data set. For the Thames basin, and using the weather generator described by Kilsby et al. (2007), Manning et al. (2009) found an increase of about $90 \%$ in winter and $50 \%$ in summer for the $2080 \mathrm{~s}$ under the A2 emissions scenario, which is consistent with the values shown in Figure 9 and obtained here for a much closer period.

As a conclusion, changes in PET obtained here are generally consistent with other studies having implemented different formulations, with reasonably similar orders of magnitude. Moreover, based on their analysis derived from various climate projections, Kay and Davies (2008) argue that "the hydrological impact uncertainty due to PE formulation is less than due to GCM structure, or even RCM structure", which reinforces the confidence on the analysis performed in Section 5.1 about the sources of uncertainty.

Natural variability, robustness of hydrological models and drought extremes. Several comments can be made on the suitability of the approach described here for simulating potential drought extremes in the future. The first one is related to the suitability of the hydrological modelling approach adopted here for simulating drought extremes. Previous studies projected a decrease in summer low flows for the 2020s in the UK (Arnell et al., 1997; Arnell, 2002), and models developed in this study should be able to simulate the hydrological behaviour of catchments during the periods of very low flows. The ability of models in simulating such future droughts can be partly assessed by investigating their performance during the benchmark 1976 drought, which was the most severe within the 1961-1990 period in most of the UK in terms of surface flow (Cole and Marsh, 2006; Marsh et al., 2007; Wade and Vidal, 2007). A specific analysis has been performed on 5 catchments (66011, 60002, 27028, 48004 and 43005, see the NRFA database for details) with areas around $200 \mathrm{~km}^{2}$ and with various combinations of BFI (0.28 to 0.90) and standard average annual rainfall $(744 \mathrm{~mm}$ to $2041 \mathrm{~mm}$ ). The very low summer flows appear to be well simulated in all 5 catchments (not shown), proving the robustness of the hydrological modelling approach adopted here.

However, the stability of parameters in a non stationary climate is not fully guaranteed, as demonstrated for example by Merz et al. (2011). They calibrated hydrological models on Austrian catchments for several consecutive 5-year periods and found significant biases in validation due to changes in climatic conditions. Based on modelling experiments in Australian catchments, Vaze et al. 
(2010) demonstrated that rainfall-runoff models calibrated with more than 20 years of observed data can be used in climate change impact studies when absolute changes in mean annual rainfall remain lower than 15 to $20 \%$. Their conclusions therefore support the approach adopted for the present study where (1) the majority of catchments used more than 20 years of observed data for calibration and (2) absolute changes in annual rainfall is limited to $10 \%$ for the whole of the UK until the 2050s (see Murphy et al., 2009, table 4.5).

Another issue concerns the use of climate change factors - even if they are probabilistic - for deriving future climate time series. Such an approach does indeed not incorporate potential changes in natural variability that would lead for example to multi-year droughts. Therefore, the guidelines elaborated for UKWIR (Vidal and Wade, 2007a) describe various approaches depending on the availability of data and tools and for example include resampling approaches that may help taking account of natural variability. It has to be mentioned that the UKCP09 climate projections are accompanied by a weather generator (Kilsby et al., 2007) able to simulate climate time series conditioned by UKCP09 probabilistic changes (Jones et al., 2009). Such a tool may in principle be useful to incorporate the effects of a changing natural variability, but as pointed out by Hall et al. (2011), simulated "year-to-year patterns are independent, so multiyear droughts occur no more frequently than would be expected under the assumption of independent annual totals".

From climate change impact assessments to global change impact assessments. The present work only considered the effect on river flows consecutive to changes in climate, with the underlying assumption that no changes will occur in the catchment. This assumption is shared by the vast majority of recent studies, and results should be used as such. In particular, no information is given about the actual flow projected in the 2020s, which will depend on (1) changes in land use that will affect the climate-runoff processes and (2) changes in water use and water management that will affect the actual flow in the river. A global change impact assessment study would thus require, on top of climate change scenarios : (1) scenarios of land use change (vegetation, soils, etc.), (2) scenarios of water use based on water demand for drinking water, irrigation or hydropower (Vidal and Hendrickx, 2010, see for example), but also (3) scenarios of water management for taking account of changes in management rules as a consequence of changes in resource. Such an integrated study would therefore require information highly specific to each catchment or water resource zone considered and could hardly be considered for national-scale assessments like the one presented here.

\section{Implications of UKCP09 for UK water resource planning}

The initial comparison of the impacts of climate change on river flows using UKWIR06 and UKCP09 indicate slightly more conservative estimates of flow reductions in the summer and smaller flow increases in winter in UKCP09 although the uncertainties tend to be larger, mainly in summer. The implications 
of the differences in results between UKCP09 and UKWIR06 for water resources will be catchment and water resource zone specific. The overall implication for water resources planning is that central estimates of Deployable Outputs (DO, the amount of water available to maintain water supply) may change, although based on the results only minor changes in DO are anticipated.

For already vulnerable catchments in the south-east and Anglian regions water resource plans may need to be revised to take account of these larger flow reductions and associated uncertainties. In the northern and western part of the UK changes in annual flow appear to be slightly positive although inter-annual variations could affect water resource availability. Smaller winter flow increases under UKCP09 may marginally reduce recharge estimates and reservoir DO whereas smaller reductions in summer flows in UKCP09 may improve estimates of DO for any run-of-river schemes for the 2020s period. The results are broadly in line with those of the European ENSEMBLES climate work (Morse et al., 2009), which indicated decreasing water availability in southern Europe and increasing water availability in northern basins. The UKCIP09 indicates a similar divide between the north and south of the UK. The ENSEMBLES project looked at projections for 2100 and this may be an indication that the trends observed for the 2020s will persist into the future.

Few water companies have yet re-assessed source yields using UKCP09. Welsh Water and Thames Water are in the process of utilising the probabilistic data for re-assessing source yields and associated uncertainties but no standard agreed methodology has been developed. The 20 sets of monthly climate factors and flow factors for the 70 model catchments are available from this study and depending on the water resource system either of these datasets can be used in existing hydrological and water resource models. Currently the main limitation for the water companies is the inability to run their systems models in batch mode, which means that running 20 climate scenarios can be onerous. Computer advances however does mean that more of the water companies will be able to run multiple scenarios in future.

The Environment Agency is currently running a number of research projects that will lead to development of guidance for using UKCP09, the RCMs and the Weather Generator data for the next generation of water resource management plans due in 2012. Whilst these projects are still in progress, indications are that water resource planning will move towards a more risk based system with the level of climate change risk analysis being tightly linked to system vulnerabilities and planned investment. Simple sensitivity analysis may be carried out initially based on changes in critical climate variables indicated by UKCP09 to determine whether further detailed analysis will be required. More targeted sampling of UKCP09 is also considered focusing the impact assessment on those projections likely to cause a problem for water supply for particular systems.

\section{Conclusions}

This study has developed a practical approach to undertaking an initial climate change impact assessments on river flows in the UK at the national 
scale using the recent probabilistic UKCP09 scenarios and a multi-modelling approach. The outcome of the study is a comprehensive database of future impacts of climate change for the 2020s on river flows for 70 catchments across the UK which can be used by the water industry for water resource impact assessments.

The analysis of the impacts of climate change using the UKCP09 scenarios indicates that for the 2020s and Medium emissions scenario: (1) winters are most likely to be warmer and wetter and summers will be warmer and drier in the 2020s compared to the 1961-1990 period; (2) uncertainties in climate modelling are large, particularly in summer with a small proportion of climate projections indicating drier winters and wetter summers; and (3) a small increase in winter flows is projected over the north-western part of the UK, whereas in all other catchments, a decrease in river flows is visible all year round. Overall the results indicate that in most lowland basins river flows are likely to be lower all year around. Within the modelling framework, this is due to inclusion of some projections with drier winters combined with a higher PET all year round, tipping the water balance of vulnerable basins in the south-east England and Anglian regions.

Compared to the previous climate change impact assessment UKWIR06, results indicate that overall river flows will be marginally lower with reduced flows in spring, summer and autumn particularly in the south-east. For most catchments the central estimates from the UKWIR06 flow factors were greater in January to April, indicating higher winter flows than the UKCP09 flow factors. Similarly the UKWIR06 flow factors were lower in most catchments in May and August, indicating lower spring and summer flows than the UKCP09 factors. These differences are due primarily to the choice of climate models, wider range of models and better representation of natural variability in UKCP09.

This study successfully provided a first look at the impacts of the UKCP09 projections on UK river flows for the 2020s and will form the basis for further research into practical uses of the probabilistic projections and development of guidelines and methods for future water resource plans.

\section{Acknowledgements}

This research was supported by research funding from UK Water Industry Research Ltd. through the project 09/CL/04/11: "Assessment of the significance to water resource management plans of the UKCP09 scenarios". The authors thank the Met Office for the provision of baseline climate data.

\section{References}

Arnell, N., Reynard, N., 2007. Water Resources Planning Guidelines - Supplementary guidance to Chapter 8: Climate change implications in estimates of water resource zone deployable output. Environment Agency report. Environment Agency. 
Arnell, N.W., 2002. Effects of Climate Change on River Flows and Groundwater Recharge: UKCIP02 scenarios. UKWIR Report 03/CL/04/2.

Arnell, N.W., Delaney, E.K., 2006. Adapting to climate change: Public water supply in England and Wales. Climatic Change 78, 227-255.

Arnell, N.W., Reynard, N.S., King, R., Prudhomme, C., Branson, J., 1997. Effects of climate change on river flows and ground water recharge: guidelines for resource assessment. UKWIR Report 97/CL/04/1. UKWIR/Environment Agency.

Bell, V.A., Gedney, N., Kay, A.L., Smith, R.N.B., Jones, R.G., Moore, R.J., 2011. Estimating potential evaporation from vegetated surfaces for water management impact assessments using climate model output. Journal of Hydrometeorology 12, 1127-1136.

Bell, V.A., Kay, A.L., Jones, R.G., Moore, R.J., 2007. Use of a grid-based hydrological model and regional climate model outputs to assess changing flood risk. International Journal of Climatology 27, 1657-1671.

Betts, R.A., Boucher, O., Collins, M., Cox, P.M., Falloon, P.D., Gedney, N., Hemming, D.L., Huntingford, C., Jones, C.D., Sexton, D.M.H., Webb, M.J., 2007. Projected increase in continental runoff due to plant responses to increasing carbon dioxide. Nature 448, 1037-1041.

Beven, K., 1993. Prophecy, reality and uncertainty in distributed hydrological modelling. Advances in Water Resources 16, 41-51.

Beven, K.J., 2000. Uniqueness of place and process representations in hydrological modelling. Hydrology and Earth System Sciences 4, 203-213.

Beven, K.J., Binley, A.M., 1992. The future of distributed models - Model calibration and uncertainty prediction. Hydrological Processes 6, 279-298.

Beven, K.J., Romanowicz, R.J., Wade, S.D., Vidal, J.P., Barnett, C., 2006. A strategy for evaluating uncertainty in assessing the impacts of climate change on water resources. Effect of climate change on river flows and groundwater recharge. A practical methodology. UKWIR Report 05/CL/04/6, ISBN 184057-396-1. 49 p. + app.

Blasone, R.S., Madsen, H., Rosbjerg, D., 2008. Uncertainty assessment of integrated distributed hydrological models using GLUE with Markov chain Monte Carlo sampling. Journal of Hydrology 353, 18-32.

de Boor, C., 1978. A Practical Guide to Splines. Springer-Verlag.

Bower, D., Hannah, D.M., McGregor, G.R., 2004. Techniques for assessing the climatic sensitivity of river flow regimes. Hydrological Processes 18, 25152543. 
Bradford, R., Marsh, T.J., 2003. Defining a network of benchmark catchments for the UK. Proceedings of the Institution of Civil Engineers. Water and Maritime Engineering 156, 109-116.

Cameron, D., 2006. An application of the UKCIP02 climate change scenarios to flood estimation by continuous simulation for a gauged catchment in the northeast of Scotland, UK (with uncertainty). Journal of Hydrology 328, $212-226$.

CCIRG, 1991. The potential impacts of climate change in the United Kingdom. First report of the United Kingdom Climate Change Impacts Review Group. Department of the Environment. HMSO, London, UK.

CCIRG, 1996. Review of the potential effects of climate change in the United Kingdom : second report. Second Report of the United Kingdom Climate Change Impacts Review Group. UK Department of Environment. HMSO, London, UK.

Charlton, M.B., Arnell, N.W., 2011. Adapting to climate change impacts on water resources in England - An assessment of draft Water Resources Management Plans. Global Environmental Change 21, 238-248.

Choi, H.T., Beven, K.J., 2007. Multi-period and multi-criteria model conditioning to reduce prediction uncertainty in an application of TOPMODEL within the GLUE framework. Journal of Hydrology 332, 316-336.

Christensen, J.H., Christensen, O.B., 2007. A summary of the PRUDENCE model projections of changes in European climate by the end of this century. Climatic Change 81, Supplement 1, 7-30.

Cloke, H.L., Jeffers, C., Wetterhall, F., Byrne, T., Lowe, J., Pappenberger, F., 2010. Climate impacts on river flow: projections for the Medway catchment, UK, with UKCP09 and CATCHMOD. Hydrological Processes 24, 34763489.

Cole, G.A., Marsh, T.J., 2006. The impact of climate change on severe droughts. Major droughts in England and Wales from 1800 and evidence of impact. Science Report SC040068/SR1. Environment Agency.

Diaz-Nieto, J., Wilby, R.L., 2005. A comparison of statistical downscaling and climate change factor methods: impacts on low flows in the River Thames, United Kingdom. Climatic Change 69, 245-268.

Ekström, M., Jones, P.D., Fowler, H.J., Lenderink, G., Buishand, T.A., Conway, D., 2007. Regional climate model data used within the SWURVE project 1: projected changes in seasonal patterns and estimation of PET. Hydrology and Earth System Sciences 11, 1069-1083.

Environment Agency, 2003. Water resources planning guideline. EA Report version 3.3, December. 
Environment Agency, 2007. Water resources planning guideline. EA Report, April.

Environment Agency, 2008. Water resources planning guideline. EA Report, November.

Environment Agency, 2009a. Water for people and the environment - Water Resources Strategy for England and Wales. EA Report, March.

Environment Agency, 2009b. Water resources strategy - Regional action plan for Thames Region. EA Report, December.

Fowler, H.J., Tebaldi, C., Blenkinsop, S., 2008. Probabilistic estimates of climate change impacts on flows in the River Eden, Cumbria, in: Proceedings of the BHS 10th National Hydrology Symposium. Sustainable Hydrology for the 21st Century, Exeter, UK. pp. 416-423.

Freer, J., Beven, K.J., Ambroise, B., 1996. Bayesian estimation of uncertainty in runoff prediction and the value of data: An application of the GLUE approach. Water Resources Research 32, 2161-2173.

Goldstein, M., Rougier, J., 2004. Probabilistic formulations for transferring inferences from mathematical models to physical systems. SIAM Journal on Scientific Computing 26, 467-487.

Hall, J.W., Watts, G., Keil, M., de Vial, L., Street, R., Conlan, K., O'Connell, P.E., Beven, K.J., Kilsby, C.G., 2011. Towards risk-based water resources planning in England and Wales under a changing climate. Water and Environment Journal .

Hannaford, J., Marsh, T.J., 2006. An assessment of trends in UK runoff and low flows using a network of undisturbed catchments. International Journal of Climatology 26, 1237-1253.

Hannaford, J., Marsh, T.J., 2008. High-flow and flood trends in a network of undisturbed catchments in the UK. International Journal of Climatology 28, $1325-1338$.

Hintze, J.L., Nelson, R.D., 1998. Violin plots: A box plot-density trace synergism. The American Statistician 52, 181-184.

Hough, M.N., Jones, R.J.A., 1997. The United Kingdom Meteorological Office rainfall and evaporation calculation system: MORECS version 2.0-an overview. Hydrology and Earth System Sciences 1, 227-239.

Hulme, M., Dessai, S., 2008. Negotiating future climates for public policy: a critical assessment of the development of climate scenarios for the UK. Environment Science and Policy 11, 54-70.

Hulme, M., Jenkins, G.J., 1998. Climate Change Scenarios for the UK: Scientific Report. Technical Report 1. UKCIP. Climatic Research Unit, Norwich, 80 p. 
Hulme, M., Jenkins, G.J., Lu, X., Turnpenny, J.R., Mitchell, T.D., Jones, R.G., Lowe, J., Murphy, J.M., Hassel, D., Boorman, P., McDonald, R., Hill, S., 2002. Climate Change Scenarios for the United Kingdom: The UKCIP02 Scientific Report. Technical Report. Tyndall Centre for Climate Change Research, School of Environmental Sciences, University of East Anglia. Norwich, UK.

IPCC, 2001. Climate Change 2001: The Scientific Basis. Contribution of Working Group I to the Third Assessment Report of the Intergovernmental Panel on Climate Change. Cambridge University Press, Cambridge, United Kingdom and New York, NY, USA.

Jones, P.D., Kilsby, C.G., Harpham, C., Glenis, V., Burton, A., 2009. Projections of future daily climate for the UK from the Weather Generator. UK Climate Projections Report. University of Newcastle. Newcastle, UK.

Kay, A.L., Davies, H.N., 2008. Calculating potential evaporation from climate model data: A source of uncertainty for hydrological climate change impacts. Journal of Hydrology 358, 221-239.

Kay, A.L., Davies, H.N., Bell, V.A., Jones, R.G., 2009. Comparison of uncertainty sources for climate change impacts: flood frequency in England. Climatic Change 92, 41-63.

Kilsby, C.G., Jones, P.D., Burton, A., Ford, A.C., Fowler, H.J., Harpham, C., James, P., Smith, A., Wilby, R.L., 2007. A daily weather generator for use in climate change studies. Environmental Modelling and Software 22, 17051719 .

Kingston, D.G., Todd, M.C., Taylor, R.G., Thompson, J.R., Arnell, N.W., 2009. Uncertainty in the estimation of potential evapotranspiration under climate change. Geophysical Research Letters 36, L20403.

Krause, P., Boyle, D.P., Base, F., 2005. Comparison of different efficiency criteria for hydrological model assessment. Advances in Geosciences 5, 89-97.

Lopez, A., Fung, F., New, M., Wilby, R.W., Watts, G., 2009. From climate model ensembles to climate change impacts and adaptation: A case study of water resource management in the southwest of England. Water Resources Research 45, W08419.

Manning, L., Hall, J., Fowler, H.J., Kilsby, C.G., Tebaldi, C., 2009. Using probabilistic climate change information from a multi-model ensemble for water resources assessment. Water Resources Research 45, W11411.

Marsh, T.J., Cole, G., Wilby, R.L., 2007. Major droughts in england and wales, 1800-2006. Weather 62, 87-93. 
Maurer, E.P., Hidalgo, H.G., Das, T., Dettinger, M.D., Cayan, D.R., 2010. The utility of daily large-scale climate data in the assessment of climate change impacts on daily streamflow in California. Hydrology and Earth System Sciences $14,1125-1138$.

McKay, M.D., Beckman, R.J., Conover, W.J., 1979. A comparison of three methods for selecting values of input variables in the analysis of output from a computer code. Technometrics 21, 239-245.

Merz, R., Parajka, J., Blschl, G., 2011. Time stability of catchment model parameters: Implications for climate impact analyses. Water Resources Research 47, W02531.

Moore, R.J., 1985. The probability-distributed principle and runoff production at point and basin scales. Hydrological Sciences Journal 30, 273-297.

Moore, R.J., 2007. The PDM rainfall-runoff model. Hydrology and Earth System Sciences 11, 483-499.

Morse, A., C., P., Carter, T., 2009. Assessments of climate change impacts, in: van der Linden, P., Mitchell, J.F.B. (Eds.), ENSEMBLES: climate change and its impacts: Summary of research and results from the ENSEMBLES project. Met Office Hadley Centre, Exeter, UK. chapter 9, pp. 107-129.

Murphy, C., Fealy, R., Charlton, R., Sweeney, J., 2006. The reliability of an offthe-shelf conceptual rainfall runoff model for use in climate impact assessment: uncertainty quantification using Latin hypercube sampling. Area 38, 65-78.

Murphy, J.M., Booth, B.B.B., Collins, M., Harris, G.R., Sexton, D.M.H., Webb, M.J., 2007. A methodology for probabilistic predictions of regional climate change from perturbed physics ensembles. Philosophical Transactions of the Royal Society Series A 365, 1993-2028.

Murphy, J.M., Sexton, D.M.H., Jenkins, G.J., Booth, B.B.B., Brown, C.C., Clark, R.T., Collins, M., Harris, G.R., Kendon, E.J., Betts, R.A., Brown, S.J., Humphrey, K.A., McCarthy, M.P., McDonald, R.E., Stephens, A., Wallace, C., Warren, R., Wilby, R., Wood, R.A., 2009. Climate change projections. UK Climate Projections Science Report. Met Office Hadley Centre. Exeter.

Nakićenović, N., Alcamo, J., Davis, G., de Vries, B., Fenhann, J., Gaffin, S., Gregory, K., Grübler, A., Jung, T.Y., Kram, T., La Rovere, E.L., Michaelis, L., Mori, S., Morita, T., Pepper, W., Pitcher, H., Price, L., Riahi, K., Roehrl, A., Rogner, H.H., Sankovski, A., Schlesinger, M., Shukla, P., Smith, S., Swart, R., van Rooijen, S., Victor, N., Dadi, Z., 2000. Special Report on Emissions Scenarios. Cambridge University Press.

Nash, J.E., Sutcliffe, J.V., 1970. River Flow Forecasting Through Conceptual Models. Part 1: A Discussion of Principles. Journal of Hydrology 10, 282-290. 
New, M., Lopez, A., Dessai, S., Wilby, R., 2007. Challenges in using probabilistic climate change information for impact assessments: an example from the water sector. Philosophical Transactions of the Royal Society Series A 365, $2117-2131$.

Oudin, L., Hervieu, F., Michel, C., Perrin, C., Andréassian, V., Anctil, F.c., Loumagme, C., 2005a. Which potential evapotranspiration input for a lumped rainfall-runoff model? Part 2-Towards a simple and efficient potential evapotranspiration model for rainfallrunoff modelling. Journal of Hydrology 303, 290-306.

Oudin, L., Michel, C., Anctil, F.c., 2005b. Which potential evapotranspiration input for a lumped rainfall-runoff model? Part 1-Can rainfall-runoff models effectively handle detailed potential evapotranspiration inputs? Journal of Hydrology 303, 275-289.

Perry, M., Hollis, D., 2005. The generation of monthly gridded datasets for a range of climatic variables over the UK. International Journal of Climatology $25,1041-1054$.

Perry, M., Hollis, D., Elms, M., 2009. The generation of daily gridded datasets of temperature and rainfall for the UK. Climate Memorandum 24. Met Office, National Climate Information Centre. Exeter, UK.

Prudhomme, C., Davies, H., 2009a. Assessing uncertainties in climate change impact analyses on the river flow regimes in the UK. Part 1: baseline climate. Climatic Change 93, 177-195.

Prudhomme, C., Davies, H., 2009b. Assessing uncertainties in climate change impact analyses on the river flow regimes in the UK. Part 2: future climate. Climatic Change 93, 197-222.

Prudhomme, C., Jakob, D., Svensson, C., 2003. Uncertainty and climate change impact on the flood regime of small UK catchments. Journal of Hydrology $277,1-23$.

Prudhomme, C., Piper, B., Osborn, T., Davies, H., 2005. Climate change uncertainty in water resource planning. UKWIR report 05/CL/04/4, ISBN 1-84057-389-9.

Romanowicz, R.J., Beven, K.J., 2006. Comments on generalised likelihood uncertainty estimation. Reliability Engineering \& System Safety 91, 13151321.

Romanowicz, R.R., 2007. Data Based Mechanistic model for low flows: Implications for the effects of climate change. Journal of Hydrology 336, 74-83.

Sauquet, E., Dupeyrat, A., Perrin, C., Agosta, C., Hendrickx, F., Vidal, J.P., 2009. Impact of business-as-usual water management under climate change for the Garonne catchment (France), in: IOP Conference Series: Earth and Environmental Science, IARU. 
Senbeta, D.A., Shamseldin, A.Y., O'Connor, K.M., 1999. Modification of the probability-distributed interacting storage capacity model. Journal of Hydrology $224,149-168$.

Shaw, S.B., Riha, S.J., 2011. Assessing temperature-based pet equations under a changing climate in temperate, deciduous forests. Hydrological Processes $25,1466-1478$.

Shirmohammadi, A., Chu, T.W., Montas, H.J., 2008. Modeling at catchment scale and associated uncertainties. Boreal Environment Research 13, 185-193.

Stainforth, D.A., Downing, T.E., Washington, R., Lopez, A., New, M., 2007. Issues in the interpretation of climate model ensembles to inform decisions. Philosophical Transactions of the Royal Society Series A 365, 2163-2177.

Stein, M., 1987. Large sample properties of simulations using Latin Hypercube Sampling. Technometrics 29, 143-151.

Stocki, R., 2005. A method to improve design reliability using optimal Latin hypercube sampling. Computer Assisted Mechanics and Engineering Sciences $12,393-411$.

von Storch, H., Zwiers, F., 1999. Statistical analysis in climate research. Cambridge University Press, Cambridge.

Subak, S., 2000. Climate change Adaptation in the U.K. water industry: Managers' perceptions of past variability and future scenarios. Water Resources Management 14, 137-156.

Vaze, J., Post, D.A., Chiew, F., Perraud, J.M., Viney, N.R., Teng, J., 2010. Climate non-stationarity - Validity of calibrated rainfall-runoff models for use in climate change studies. Journal of Hydrology 394, 447-457.

Vidal, J.P., Hendrickx, F., 2010. Impact of Climate Change on Hydropower: Ariège, France, in: Fung, F., Lopez, A., New, M. (Eds.), Modelling the Impact of Climate Change on Water Resources. Wiley-Blackwell. chapter 6.3, pp. $148-161$.

Vidal, J.P., Wade, S.D., 2007a. Guidelines for resource assessment and UKWIR06 scenarios. Effect of climate change on river flows and groundwater recharge. A practical methodology. UKWIR Report 06/CL/04/8, ISBN 184057-431-3.

Vidal, J.P., Wade, S.D., 2007b. Synthesis Report. Effect of climate change on river flows and groundwater recharge. A practical methodology. UKWIR Report 06/CL/04/10, ISBN 1-84057-443-7.

Vidal, J.P., Wade, S.D., 2008a. A framework for developing high-resolution multi-model climate projections: 21st century scenarios for the UK. International Journal of Climatology 28, 843-858. 
Vidal, J.P., Wade, S.D., 2008b. Multimodel projections of catchment-scale precipitation regime. Journal of Hydrology 353, 143-158.

Vidal, J.P., Wade, S.D., 2009. A multimodel assessment of future climatological droughts in the United Kingdom. International Journal of Climatology 29, 2056-2071.

von Christierson, B., Wade, S.D., Rance, J., 2009. Assessment of the significance to water resource management plans of the UK Climate Projections 2009. UKWIR Report 09/CL/04/11, ISBN 1-84057-547-6.

Vrugt, J.A., ter Braak, C.J.F., Gupta, H.V., Robinson, B.A., 2009. Equifinality of formal (DREAM) and informal (GLUE) Bayesian approaches in hydrologic modeling? Stochastic Environmental Research and Risk Assessment 23, 1011-1026.

Wade, S.D., Vidal, J.P., 2007. Draft Water Resource Plan: Trends in hydrological variables and drought frequency in Wales. HR Wallingford Report EX 5457. Dîr Cymru/Welsh Water.

Wade, S.D., Vidal, J.P., Dabrowski, C., Young, P.C., Romanowicz, R.J., 2005. Trends in UK river flows: 1970-2002. Effect of climate change on river flows and groundwater recharge. A practical methodology. UKWIR Report 05/CL/04/5, ISBN 1-84057-387-2. 37 p. + annexes.

Wade, S.D., Vidal, J.P., Romanowicz, R.J., Beven, K.J., 2006. Interim report on rainfall-runoff modelling. Effect of climate change on river flows and groundwater recharge. A practical methodology. UKWIR Report 06/CL/04/7, 184057-421-6. 38 p. + annexes.

Wilby, R.L., 2005. Uncertainty in water resource model parameters used for climate change impact assessment. Hydrological Processes 19, 3201-3219.

Wilby, R.L., Greenfield, B., Glenny, C., 1994. A coupled synoptic-hydrological model for climate change impact assessment. Journal of Hydrology 153, 265290.

Wilby, R.L., Harris, I., 2006. A framework for assessing uncertainties in climate change impacts: Low-flow scenarios for the River Thames, UK. Water Resources Research 42, W02419.

Wilks, D.S., 2006. Statistical methods in the atmospheric sciences. volume 91 of International Geophysics Series. Academic Press, New York. 2nd edition.

Wood, A., 2005. Report on rainfall-runoff modelling using PDM and Catchmod. Technical Report. Lancaster University, Department of Environmental Science.

Wood, A.W., Maurer, E., Kumar, A., Lettenmaier, D.P., 2002. Long-range experimental hydrologic forecasting for the eastern United States. Journal of Geophysical Research 107, 4429. 
WSAtkins, 2002. Water Resources Modelling Strategy and Programme - Catchmod - User Manual. Technical Report. Environment Agency.

Young, A.R., 2002. River flow simulation within ungauged catchments using a daily rainfall-runoff model, in: Littlewood, I. (Ed.), Continuous river flow simulation: methods, applications and uncertainties. British Hydrological Society. number 13 in BHS Occasional Paper, pp. 31-38. 